\title{
Self Tuning PID Control of Antilock Braking System using Electronic Wedge Brake
}

\author{
S. I. Haris ${ }^{1,2}$, F. Ahmad ${ }^{1,}{ }^{*}$, M. H. Che Hassan ${ }^{3}$, A. K. Mat Yamin ${ }^{1}$ and N. R. Mat Nuri 4
}

${ }^{1}$ Faculty of Mechanical Engineering, Universiti Teknikal Malaysia Melaka (UTeM), 76100 Hang Tuah Jaya, Melaka, Malaysia ${ }^{2}$ Kolej Kemahiran Tinggi MARA Masjid Tanah, Km 1, Persiaran Paya Lebar, Ramuan China Besar, 78300 Masjid Tanah, Melaka, Malaysia ${ }^{3}$ Faculty of Electrical and Electronic Engineering Technology, Universiti Teknikal Malaysia Melaka (UTeM), 76100 Hang Tuah Jaya, Melaka, Malaysia

${ }^{4}$ Faculty of Mechanical and Manufacturing Engineering Technology, Universiti Teknikal Malaysia Melaka (UTeM), 76100 Hang Tuah Jaya, Melaka, Malaysia

\begin{abstract}
This paper describes the design of an antilock braking system (ABS) control for a passenger vehicle that employs an electronic wedge brake (EWB). The system is based on a twodegree-of-freedom (2-DOF) vehicle dynamic traction model, with the EWB acting as the brake actuator. The developed control structure, known as the Self-Tuning PID controller, is made up of a proportional-integral-derivative (PID) controller that serves as the main feedback loop control and a fuzzy supervisory system that serves as a tuner for the PID controller gains. This control structure is generated through two structures, namely FPID and SFPID, where the difference between these two structures is based on the fuzzy input used. An ABS-based PID controller and a fuzzy fractional PID controller developed in previous works were used as the benchmark, as well as the testing method, to evaluate the effectiveness of the controller structure. According to the results of the tests, the performance of the SFPID controller is better than that of other PID and FPID controllers, being $10 \%$ and $1 \%$ faster in terms of stopping time, $8 \%$ and $1 \%$ shorter in terms of stopping distance, $9 \%$ and $1 \%$ faster in terms of settling time, and $40 \%$ and $5 \%$ more efficient in reaching the target slip, respectively.
\end{abstract}

ARTICLE HISTORY

Received: 29th April 2021

Revised: $7^{\text {th }}$ Sept 2021

Accepted: $15^{\text {th }}$ Dec 2021

KEYWORDS

Self-tuning PID controller; Fuzzy;

Antilock braking system;

Electronic wedge brake

\section{INTRODUCTION}

Over the last decade, the electronic wedge brake system (EWB) has been on the radar of automotive research. It is a pure electronically controlled brake actuator that has been extensively studied in automotive applications by many researchers. Despite this, studies in ABS brake testing are still underutilised. Recent studies have primarily focused on examining the functionality of the EWB system, which is primarily dependent on the low layer actuator control, while ABS control development has received less attention. Most researchers used conventional Bang-bang controller [28], PID controller [9,10,18,30,39], Fuzzy logic controller (FLC) [9,10,22], and Sliding Mode Control (SMC) [21] as ABS controller in EWB systems. The majority of earlier works claimed to attain superior dynamic performance than their respective counterpart controllers. Furthermore, it can be noted that the conventional PID and FLC controllers are two of the most popular ways for managing ABS-based EWB. It is a well-known fact that those controllers have some limitations, such as linearity in PID [2,29], static rules in FLC [28], and poor learning speed in SMC [15-16], which correspond to the requirement for controller development.

In terms of improving vehicle stopping time and stopping distance, the use of a Bang-bang controller in ABS, such as that presented in [27], outperforms the passive system. Nonetheless, the ABS has a flaw in that the Bang-bang controller is unable to track the required tire slip well due to the controller's discontinuous control [27]. Nevertheless, the disadvantage of using the Bang-bang controller in the ABS has been overcome by using the PID controller. According to $[3,9,10,18,30,39]$, the usage of PID controller in ABS has resulted in higher performance compared to the Bang-bang controller in terms of the ability to track the needed tire slip with faster response time, which enhances the vehicle's stopping distance. This is due to the PID controller's ability to continually calculate the error values between an actual and desired tire slip and apply a correction based on proportional, integral, and derivatives terms. However, the PID controller has a significant shortcoming, which is linearity in the controller, which limits the efficiency of EWB over varied vehicle speeds.

To address this issue, automobile designers have placed a greater emphasis on ABS, with a variety of control methods being developed as well as rapid continuous improvement in control schemes [42]. PID controllers [21,33,37,46], fuzzy logic controllers $[5,6,11,13,34,38,46]$, and sliding mode controllers $[8,16,19,20,33,39,41]$ have gotten a lot of attention. Additionally, researchers are investigating ABS controllers based on Lyapunov stability theory $[26,44,47]$ and other theories to create ABS controllers like adaptive time-varying restriction control [25], multiple-model switching observer (MMSO) algorithm [23], Artificial Neural Network (ANN) [13], and on-board controllers [7]. The ABS proposed in this study is based on a system that employs EWB. Previous research on this study has focused on PID controllers that operate on the basis of target slip control [18,31]. Ahmad et al. [1,3] developed the torque tracking control of the system using a 
PID controller. The controller strategy was created, including three control loops (actuator position control loop, actuator speed control loop, and brake torque control loop). Aparow et al. [10] created an ABS controller that uses PID to greatly reduce stopping distance and control longitudinal slip during heavy braking.

Further research in ABS-EWB controllers includes intelligent controllers such as the fuzzy logic scheme [9,37]. The fuzzy logic system has been compared to conventional PID, and adaptive PID aims to establish an appropriate control scheme for ABS-EWB by assessing the model's performance in terms of wheel longitudinal slip and vehicle stopping distance. Some research, such as Ahmad et al. [4], incorporate fuzzy logic with PID schemes within the ABS-EWB control strategy. In this study, the fuzzy fractional PID (FFPID) controller is applied to an antilock braking system using an electronic wedge brake mechanism to explain the need for such controllers for more efficient system control.

In ABS-EWB systems, the sliding mode controller has also been used as a controller strategy [22,40]. The controller's goal is to achieve optimal wheel slip control, and the control results show significantly shorter braking distances when compared to other conventional braking systems, such as a PID controller. Existing control techniques, such as PIDs, have implementation constraints [42]. Because of the PID controller's linearity, the EWB's performance cannot be tested at different vehicle speeds. Despite the rapid development of fuzzy logic control, there is still an opportunity for improvement [45]. For greater accuracy, the fuzzy logic controller requires more fuzzy grades, resulting in an exponential increase in the rule. Sliding mode causes control signal oscillations, which can lead to system instability and actuator disruption [7]. As a result of the speed variation, the sliding mode controller demonstrates a lack of system performance.

The EWB fifth-order linear state space form model was used to create an ABS in this study. The proposed ABS-EWB is a hydraulic-free active braking system that prevents wheels from locking during hard braking, assisting people in preserving vehicle control and stability. In addition, the ABS-EWB model employs brake-by-wire technology. Meanwhile, in this research for the ABS-EWB model, two control mechanisms are constructed and compared. Traditional PIDs and Self-Tuning PIDs through the development of two control structures, namely fuzzy logic PID (FPID) and self tuning fuzzy PID (SFPID), are among the devices available. The suggested control system's major goal is to determine which ABS-EWB controller is more important by evaluating the model's performance in terms of longitudinal slip, wheel speed, vehicle speed, and stopping distance of the vehicle.

Furthermore, as a result of the proposed control technique, attention is also placed on the vehicle ride comfort. PID control offers benefits such as a simple structure, good control effect, fast calculation time, robustness, and ease of implementation [34]. Moreover, the fuzzy logic controller can detect data imprecision, allowing it to simulate truth better than typical digital logic [11]. The advantages of fuzzy logic and the PID controller have been merged in these works to provide the PID controller with the capacity to modify its parameters when problems happen. The following is how the paper is structured: the dynamic model of the vehicle in the longitudinal direction is presented in the second section. The EWB system is presented in the second section, and the ABS' proposed control structure is presented in the following section. The fourth section evaluates the performance of proposed ABS control systems. The conclusion of this study is presented in the final section.

\section{QUARTER VEHICLE MODEL}

In this study, a validated vehicle dynamic model developed by Haris et al. [24] is used to simulate the effectiveness of an ABS control strategy. The model is based on a two degree of freedom (2-DOF) quarter vehicle traction model, as shown in Figure 1, and has been experimentally validated using a Malaysian national car, the Proton Iswara. Haris et al. [24] detail the model's derivation, the validation procedure, and the validation results of the vehicle's wheel slip, wheel, and body speed. Table 1 lists the vehicle parameters.

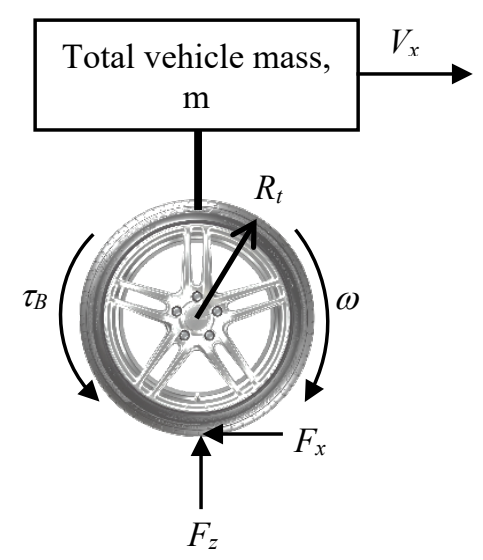

Figure 1. Quarter car model. 
Table 1. Quarter Vehicle Parameters [24].

\begin{tabular}{lc}
\hline Parameter & Value \\
\hline Total quarter vehicle mass & $240 \mathrm{~kg}$ \\
Rolling radius & $0.2 \mathrm{~m}$ \\
Wheel moment inertia & $1.4 \mathrm{kgm}$ \\
Gravity acceleration & $9.81 \mathrm{~m} / \mathrm{s}^{2}$ \\
\hline
\end{tabular}

\section{ELECTRONIC WEDGE BRAKE SYSTEM}

Figure 2 depicts the design of the EWB system, which includes the brake actuator and heart brake mechanism. The EWB is powered by a direct current motor that is directly connected to the heart brake mechanism, which comprises a wedge mechanism, a calliper, and a brake pad coupled with a lead screw (single style start). The lead screw is then connected to the heart mechanism via a no-loss planetary reduction gear to produce the requisite actuation force. The lead screw converts the angular motion of the DC motor to the axial motion of the wedge in the core of the brake.

The fifth-order linear state space form is used to derive the full EWB model, which includes the motor configuration, lead screw with gear, and EWB (brake heart) structure, as Eq. (1), where $X_{\mathrm{w}}$ denotes wedge movement, $V_{\mathrm{w}}$ denotes wedge velocity, $\theta_{m}$ denotes motor angle, $\omega_{m}$ denotes angular velocity, $I_{m}$ denotes motor current, and $F_{c}$ denotes clamping force. The Simulink model of EWB is illustrated in the appendix. Table 2 describes the physical parameters used to evaluate the EWB model, such as DC motors, brake pads, wedges, and others.

$$
\left\{\begin{array}{l}
\dot{X}=A x+B u \\
y=C x+D u
\end{array}\right.
$$

with

$$
\begin{aligned}
& x=\left[X_{w}, V_{w}, \theta_{m}, \omega_{m}, I_{m}\right]^{T} \\
& y=F_{c} \\
& A=\left[\begin{array}{ccccc}
0 & 1 & 0 & 0 & 0 \\
\frac{-K_{a}-a_{1} a_{4}^{2}}{a_{2} a_{4}^{2}} & \frac{-D_{a}}{a_{2} a_{4}^{2}} & \frac{K_{a} a_{3}}{a_{2} a_{4}} & \frac{D_{a} a_{3}}{a_{2} a_{4}} & 0 \\
0 & 0 & 0 & 1 & 0 \\
\frac{K_{a} a_{3}}{\eta J_{m} a_{4}} & \frac{D_{a} a_{3}}{\eta J_{m} a_{4}} & \frac{-K_{a} a_{3}^{2}}{\eta J_{m}} & \frac{-D_{m}}{J_{m}}-\frac{D_{a} a_{3}^{2}}{\eta J_{m}} & \frac{K_{t}}{J_{m}} \\
0 & 0 & 0 & \frac{-K_{e}}{L_{m}} & \frac{-R_{m}}{L_{m}}
\end{array}\right] \\
& B=\left[\begin{array}{c}
0 \\
0 \\
0 \\
0 \\
\frac{1}{L_{m}}
\end{array}\right] \text { and } C=\left[\begin{array}{c}
K_{\text {cal }} \tan (\alpha) \\
0 \\
0 \\
0 \\
0
\end{array}\right]^{T}
\end{aligned}
$$

where

$a_{1}=K_{\text {cal }} \tan \alpha(\tan \alpha-\mu)$

$a_{2}=M_{w}\left(\tan ^{2} \alpha+1\right)$

$a_{3}=\frac{N_{a} L_{a}}{2 \pi}$

$a_{4}=\cos \beta$,

$\beta \begin{cases}0 & \text {, for normal actuation } E W B \\ \alpha & \text {, for optimised actuation } E W B\end{cases}$

Table 2. The EWB parameters [17].

\begin{tabular}{lclc}
\hline Parameter & Value & Parameter & Value \\
\hline Motor resistance, $R_{m}$ & $0.4781 \Omega$ & Axial viscous friction constant, $D_{a}$ & $9.3279 \mathrm{e}-05$ \\
Motor inductance, $L_{m}$ & $0.0230 \mathrm{H}$ & Roller screw efficiency, $\eta$ & 0.63 \\
Electromotive force constant, $K_{e}$ & $0.0158 \mathrm{~N} . \mathrm{m} / \mathrm{A}$ & Roller screw pitch, $L_{a}$ & $3 \mathrm{e}-3 \mathrm{~m}$ \\
Torque constant, $K_{t}$ & $0.0156 \mathrm{~N} . \mathrm{m} / \mathrm{A}$ & Wedge weight, $M_{w}$ & $0.3 \mathrm{~kg}$ \\
Motor moment inertia, $J_{m}$ & $7.094 \mathrm{e}-3 \mathrm{Kg} . \mathrm{m} 2 / \mathrm{s} 2$ & Wedge angle, $\alpha$ & $24.5 \mathrm{degree}$ \\
Motor viscous friction constant, $D_{m}$ & $1.9175 \mathrm{e}-5 \mathrm{~N} . \mathrm{m} . \mathrm{s}$ & Motor axial angle, $\beta$ & $24.5 \mathrm{degree}$ \\
Gear reduction, $N_{a}$ & $1 / 24$ & Calliper stiffness, $K_{\text {cal }}$ & $44.8385 \mathrm{e} 6 \mathrm{~N} / \mathrm{m}$ \\
Axial stiffness, $K_{a}$ & $750 \mathrm{e} 6 \mathrm{~N} / \mathrm{m}$ & Brake pad coefficient, $\mu$ & 0.35 \\
\hline
\end{tabular}




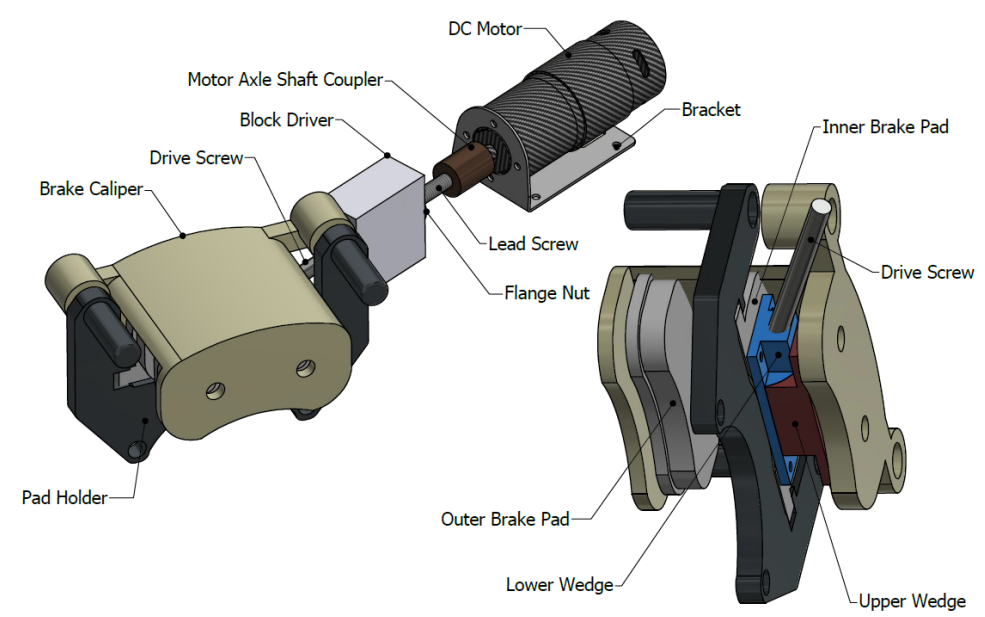

Figure 2. EWB system design.

\section{The EWB Control Structure}

Figure 3 depicts the torque tracking control of an EWB, which consists of a single control loop, the torque control loop. To keep the gap distance between the pad and the disc brake constant, this control loop employs a proportionalintegral (PI) controller. The output of the control loop, which is the actual torque, would then regulate the DC motor's position in order to track the desired torque. The Ziegler-Nichols method was used to tune the controller parameters, which are proportional gain, $k_{p}$, which is $1.3333 \times 10^{3}$, and integral gain, $k_{i}$, which is 55.77 .

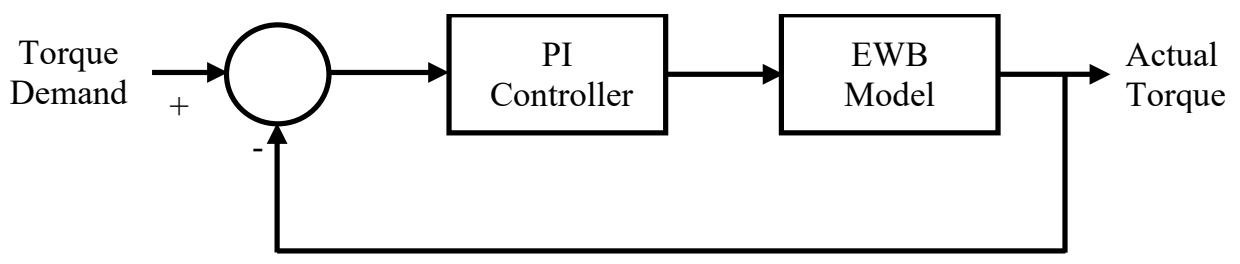

Figure 3. EWB control structure.

\section{ANTILOCK BRAKING SYSTEM CONTROL STRATEGY}

Figure 4 depicts the general structure of a conventional PID control system for ABS using EWB. The error signal $e(t)$ obtained from the differences between actual tire longitudinal slip $\left(s_{a c t}\right)$ and desired tire longitudinal slip $\left(s_{\text {des }}\right)$ triggers the PID controller's control action. The $s_{\text {des }}$ value of 0.2 is used because it is the critical tire longitudinal slip ratio that indicates a road with very low friction.

By multiplying the error by the controller weighted signals, a controller signal, $u(t)$ is produced that corresponds to the ideal torque that must be tracked by the EWB actuator. The PID controller action for the ABS and the generation of the control signal $u(t)$ can be written as $u(t)=k_{p}(t) e(t)+k_{i}(t) \int e(t) d t+k_{d}(t) \frac{d}{d t} e(t)$, where the $\int e(t)$ and $\frac{d}{d t} e(t)$ represented the integral and derivative of the error respectively, $k_{p}$ is proportional gain, $k_{i}$ is integral time constant; and $k_{d}$ is derivative time constant. By using Ziegler-Nichols tuning method [46], the parameters for $k_{p}, k_{i}$ and $k_{d}$ are set to be 4000, 100 and 1, respectively.

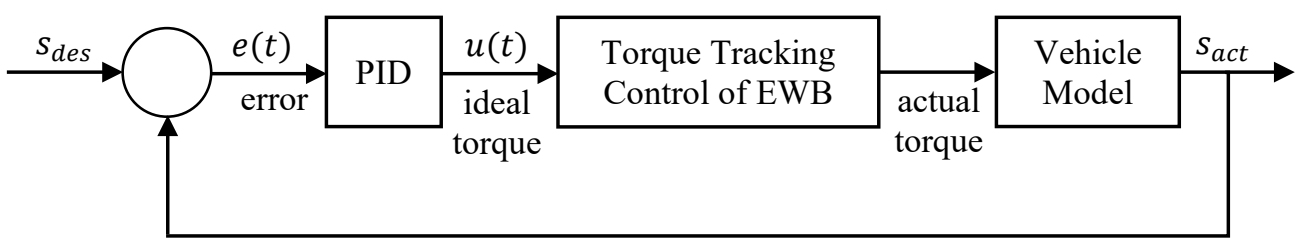

Figure 4. PID controller.

\section{Self-tuning PID Controller (Structure 1)}

A supervisory system with a fuzzy logic controller (FLC) is used to increase the rigidity of the PID controller and make the controller gains self-tuneable. Figure 5 depicts the control structure, specifically the Fuzzy PID controller (FPID), which consists of a PID controller that functions as the primary feedback loop control to observe the actual vehicle's tire longitudinal slip and a fuzzy supervisory system that functions as a tuner for the PID controller gains. Selftuning PID controller (structure 1) is named as a fuzzy PID (FPID) controller to simplify the description.

In this structure, the tire longitudinal slip error $(e)$ and error rate $(\dot{e})$ are chosen as the input variables of the fuzzy controller, while the outputs of the controller are the $k_{p}, k_{i}$, and $k_{d}$ which are the values for the PID controller. Figure 6 depicts the fuzzy supervisory system's input and output channels graphically. 


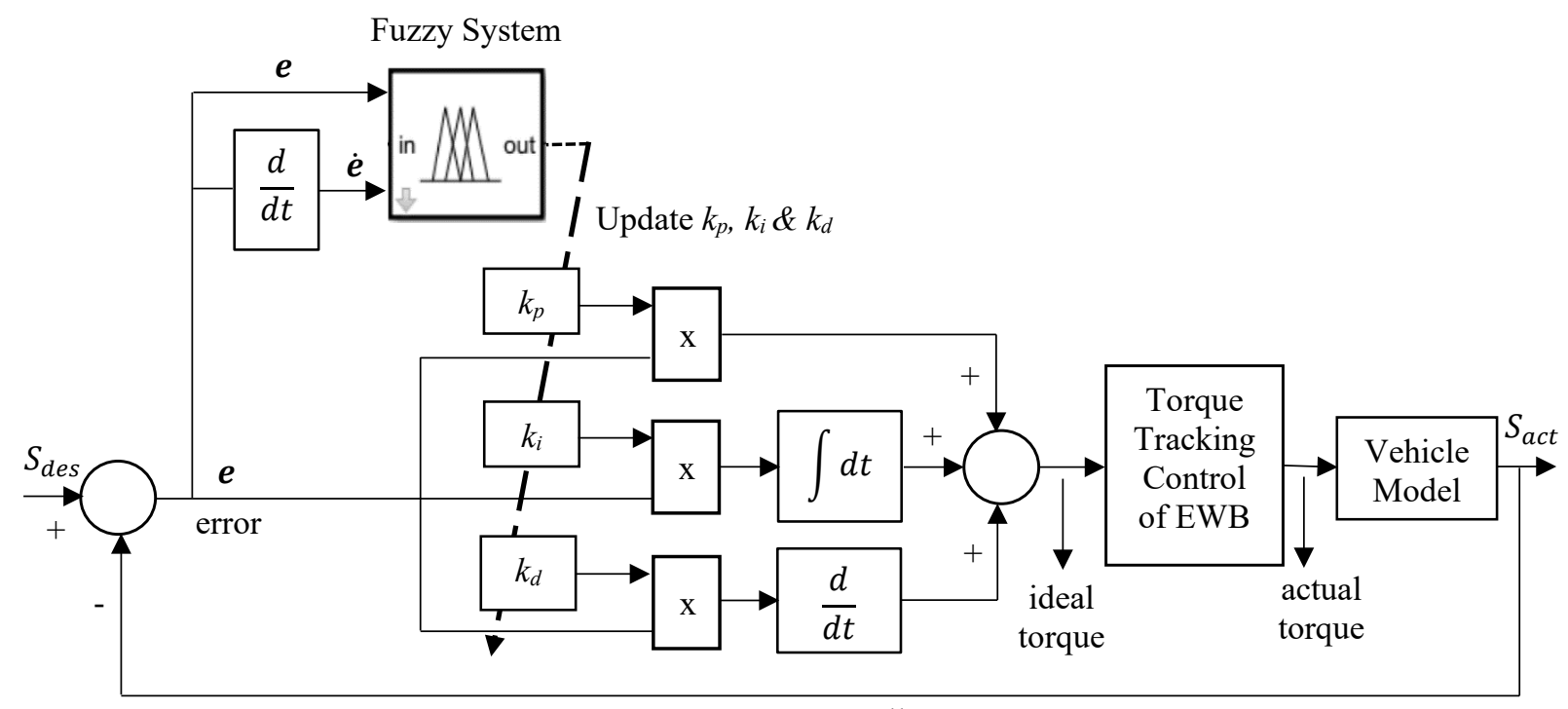

Figure 5. Fuzzy-PID controller structure.

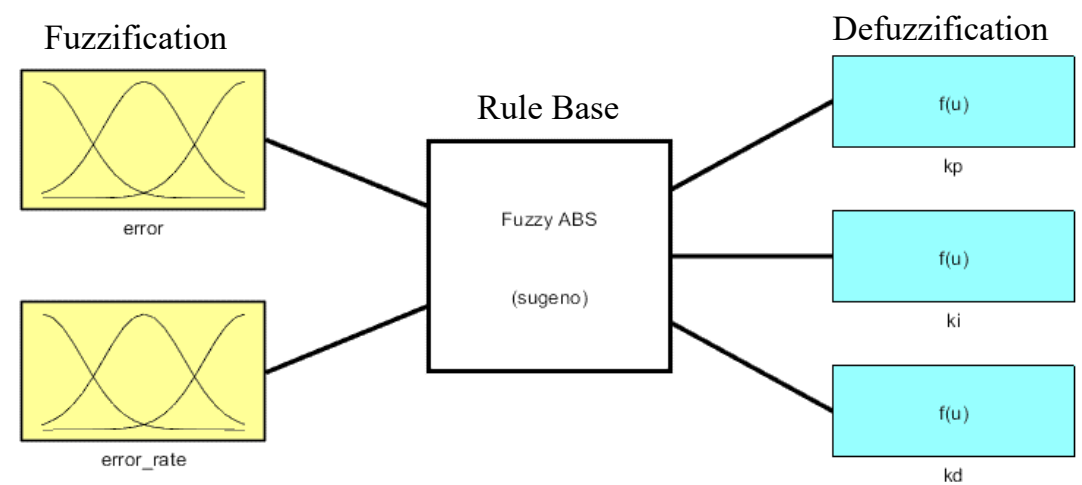

Figure 6. Fuzzy-based PID controller structure.

For the antecedent, a Gaussian-type membership function is used, and both fuzzy inputs are set to have five membership functions, namely Negative Big (NB), Negative Small (NS), Zero (Z), Positive Small (PS), and Positive Big (PB). This membership function was used to assign each of them a qualitative category, such as low, normal, or high. Figure 7(a) and 7(b) show the membership functions for error and error rate, respectively. The universe of discourse for the error, $\boldsymbol{e}$ are set to be -0.45 to 0.45 , while for the error rate, $\dot{\boldsymbol{e}}$ are -0.03 to 0.03 .

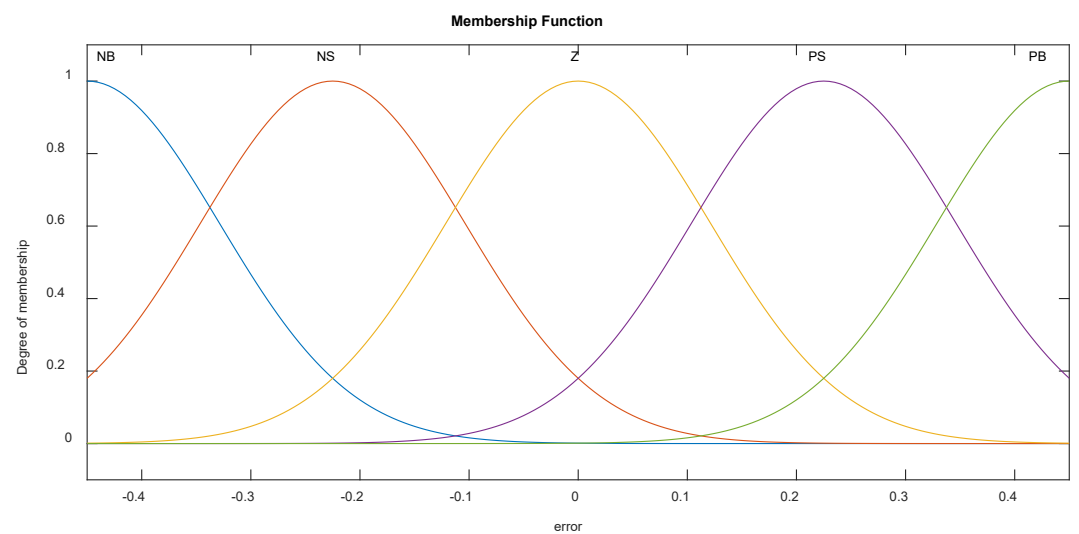

(a) 


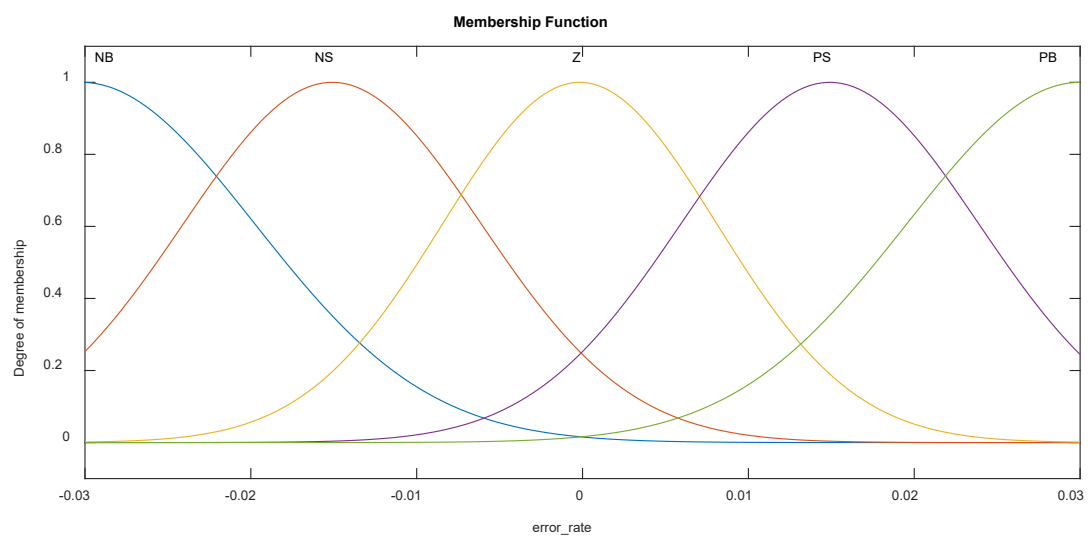

(b)

Figure 7. (a) Error (slip), and (b) error rate membership function.

The rule-base, also known as the fuzzy knowledge-decision base's matrix, is composed of expert IF THEN rules that convert the input variables into an output that indicates the likelihood of operational issues. Defuzzification is the process of converting the fuzzy set membership degrees into a specific argument or actual values for $k_{p}, k_{i}$, and $k_{d}$.

The proposed fuzzy system is deployed in each region, allowing each area to determine its own appropriate gain value. Assume there are $n$ rules, each of which takes the form:

$$
\text { rule } i \text { : IF } x \text { is } \mu \text {, THEN } u \text { is } b_{i}
$$

where $x$ is the fuzzy system's input variable, $u$ is its output variable; $\mu$ is the Gaussian membership function and $b_{i}$ is the singleton control action for $i=1,2, \ldots . . n$.

The following is the mathematical relationship for a Gaussian membership function:

$$
\mu_{i j}=\exp ^{-1 / 2}\left\{\frac{\left(x_{j}^{i}-c_{j}^{i}\right)^{2}}{\sigma_{j}^{i}}\right\}
$$

where, the $x_{j}^{i}$ is the input to the membership function; the $c_{j}^{i}$ and $\sigma_{j}^{i}$ are the center and spread of Gaussian antecedent membership function at rule $i$ and input $j$, respectively.

Aparow et al. [9] proposed a method for establishing controller rules. Based on expert hands-on knowledge and skills, the controller tunes on a regular basis in accordance with the error and error rate variance. Table 3 shows the controller rules for $k_{p}, k_{i}$, and $k_{d}$.

\begin{tabular}{|c|c|c|c|c|c|c|}
\hline \multirow{2}{*}{$k_{p} / k_{i} / k_{d}$} & \multicolumn{6}{|c|}{ error rate } \\
\hline & & NB & NS & $\mathrm{Z}$ & PS & PB \\
\hline \multirow{5}{*}{ error } & NB & $\mathrm{PB} / \mathrm{NB} / \mathrm{Z}$ & Z/NS/PB & $\mathrm{NS} / \mathrm{PB} / \mathrm{NB}$ & NB/Z/PS & $\mathrm{PS} / \mathrm{PS} / \mathrm{NS}$ \\
\hline & NS & $\mathrm{PS} / \mathrm{NS} / \mathrm{NS}$ & $\mathrm{PB} / \mathrm{NB} / \mathrm{Z}$ & NB/PS/PB & $\mathrm{Z} / \mathrm{PB} / \mathrm{NB}$ & NS/Z/PS \\
\hline & Z & $\mathrm{Z} / \mathrm{PB} / \mathrm{PS}$ & PS/PS/NB & $\mathrm{PB} / \mathrm{Z} / \mathrm{NS}$ & NS/NB/PB & NB/NS/Z \\
\hline & PS & NS/Z/NB & NB/PB/NS & Z/NS/PS & PS/PS/Z & $\mathrm{PB} / \mathrm{NB} / \mathrm{PB}$ \\
\hline & PB & NB/PS/PB & NS/Z/PS & $\mathrm{PS} / \mathrm{NB} / \mathrm{Z}$ & $\mathrm{PB} / \mathrm{NS} / \mathrm{NS}$ & $\mathrm{Z} / \mathrm{PB} / \mathrm{NB}$ \\
\hline
\end{tabular}

Table 3. Rules of controller.

The defuzzification overall output is obtained because each rule has a crisp output, as shown in Figure 8(a) to 8(c). These figures depict the relationship between error, error rate, and $k_{p} / k_{i} / k_{d}$ output in a 3D surface, with output fuzzy variables are singletons ranging from $1 \times 10^{4}$ to $4 \times 10^{4}, 2000$ to 8000 , and 0.2 to 0.8 , respectively. The fuzzy PID output is defuzzified using the central gravity method, which can be expressed as follows:

$$
\mathrm{f}(\mathrm{x} \mid \theta)=\frac{\sum_{\mathrm{i}=1}^{\mathrm{R}} \mathrm{b}_{\mathrm{i}} \prod_{\mathrm{j}=1}^{\mathrm{n}} \exp \left(-\frac{1}{2}\left(\frac{\mathrm{x}_{\mathrm{j}}-\mathrm{c}_{\mathrm{j}}^{\mathrm{i}}}{\sigma_{\mathrm{j}}^{\mathrm{i}}}\right)^{2}\right)}{\sum_{i=1}^{R} \prod_{j=1}^{n} \exp \left(-\frac{1}{2}\left(\frac{x_{j}-c_{j}^{i}}{\sigma_{j}^{i}}\right)^{2}\right)}
$$




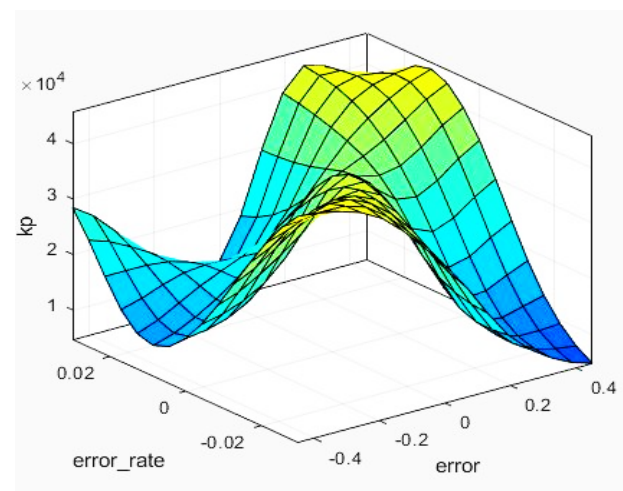

(a) $k_{p}$

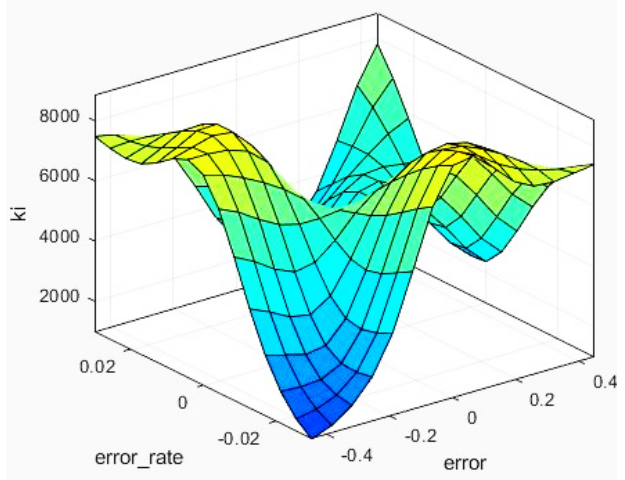

(b) $k_{i}$

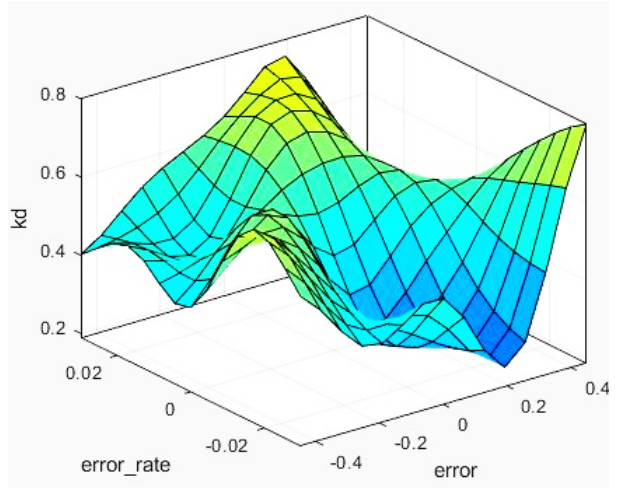

(c) $k_{d}$.

Figure 8. Defuzification ouputs.

\section{Self-tuning PID Controller (Structure 2)}

Another self-tuning PID controller designed for this ABS is the Self Tuning Fuzzy PID (SFPID) controller, as shown in Figure 9. This controller is also supervised by a fuzzy logic system and follows the rules outlined in Eq. (2), (3), and (4). The structure of the controller is nearly identical to that of the previous FPID controller, with the exception of the fuzzy controller's input variables.

In this structure, the tire longitudinal slip error $(e)$ and delta speed which is the relative velocity between body speed and wheel speed, are chosen as the input variables of the fuzzy controller, while the outputs of the controller are still the $K_{p}, K_{i}$ and $K_{d}$ which are the values for the PID controller. The rationale for using delta speed as additional input to the fuzzy controller, according to Ahmad [4], is that there is a significant change in the relative velocity between the body velocity and the wheel velocity during changes in road conditions. At the same time, the relative velocity character of the wheel and the body determines the maximum braking torque that an ABS can generate. As a result, in this investigation, delta speed as a controller input is sufficient. The input and output channels for the SFPID supervisory system are graphically depicted in Figure 10.

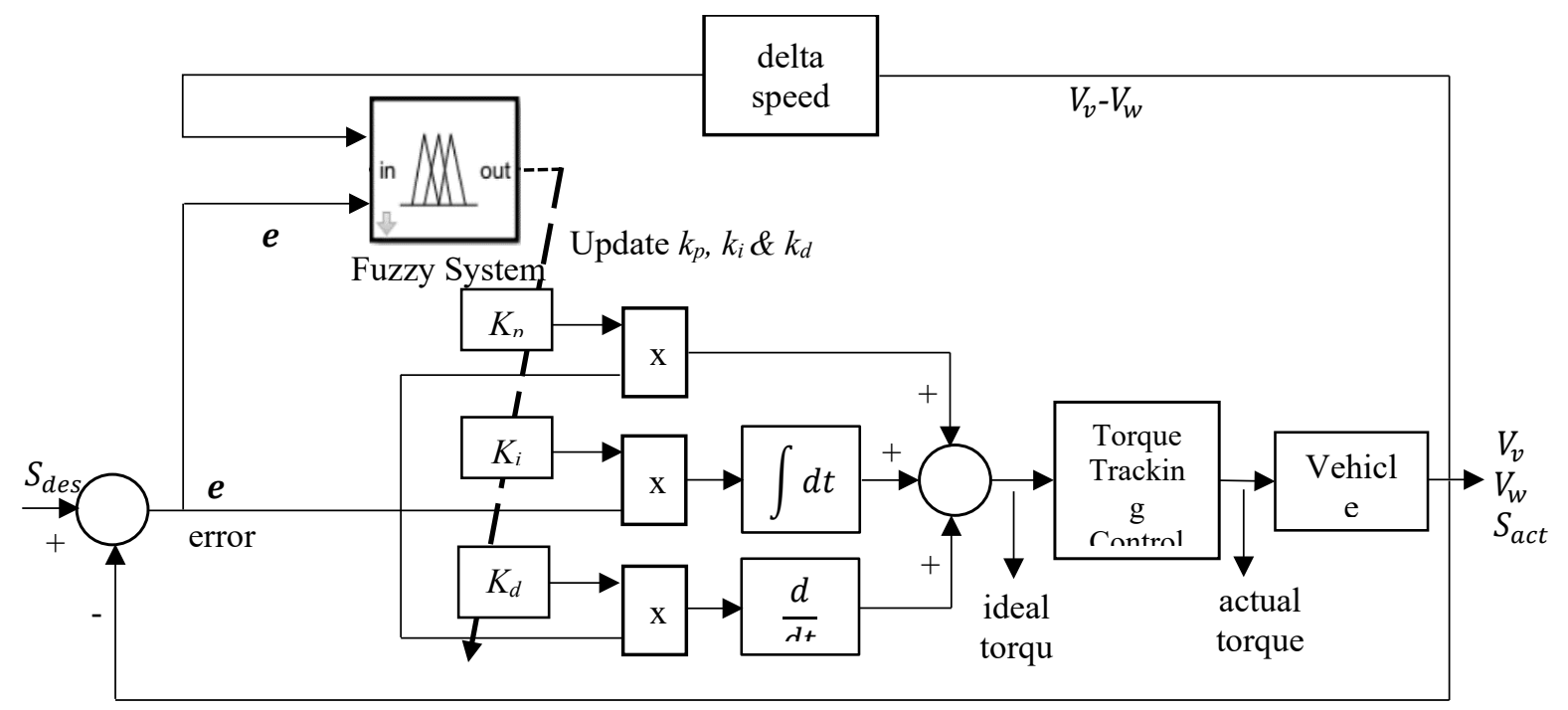

Figure 9. Self tuning fuzzy PID control structure. 


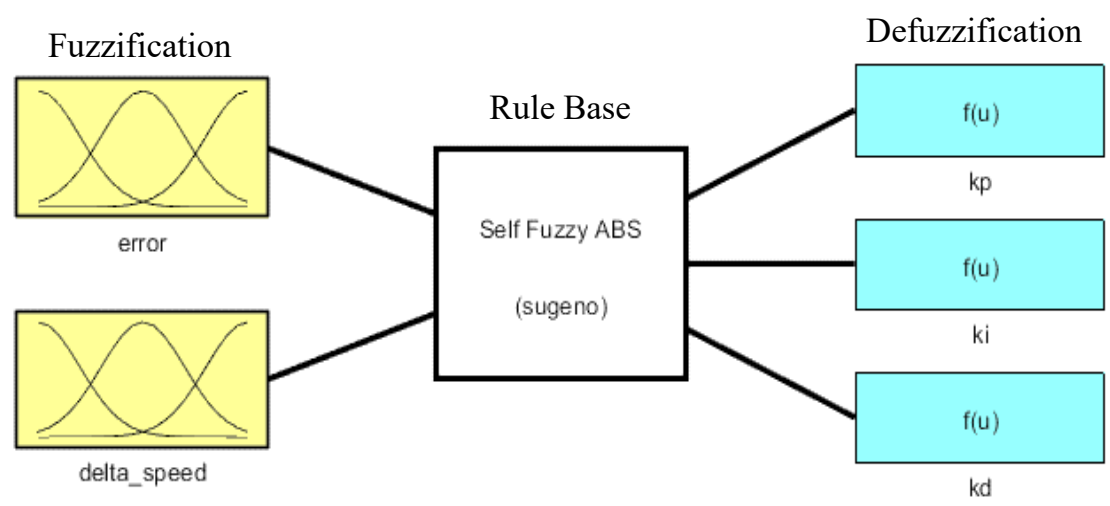

Figure 10. Self tuning fuzzy PID controller structure.

As with the previous FPID Controller, the membership function of this SFPID controller is configured in five membership features: Negative Big (NB), Negative Small (NS), Zero (Z), Positive Small (PS), and Positive Big (PB). Figure 11(a) and 11(b) show the membership functions of both error (slip) and delta velocity (relative velocity), respectively. According to these figures, the universe of discourse for the error, $\boldsymbol{e}$, is set to -0.02 to 0.02 , and the universe of discourse for the delta speed is set to -0.35 to 0.35 .

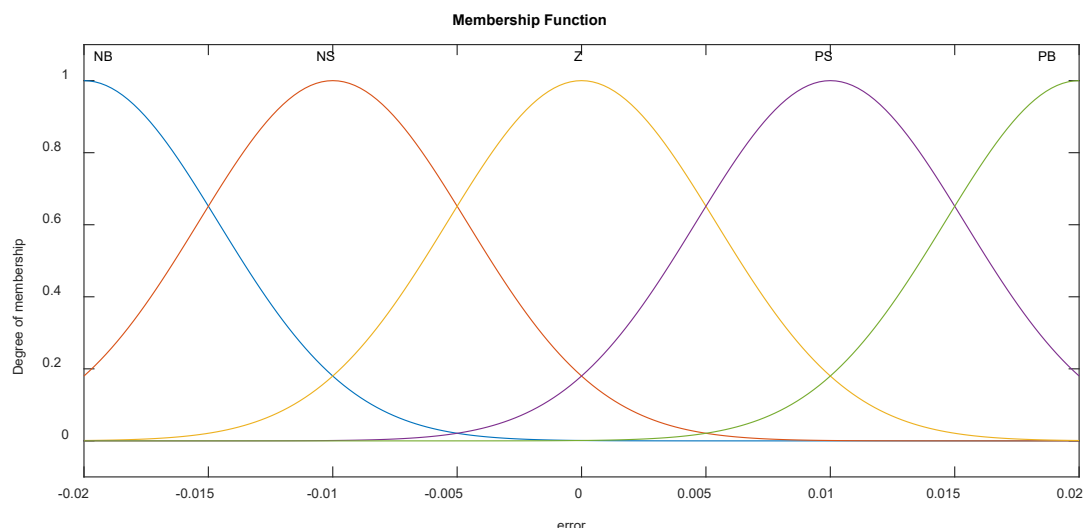

(a)

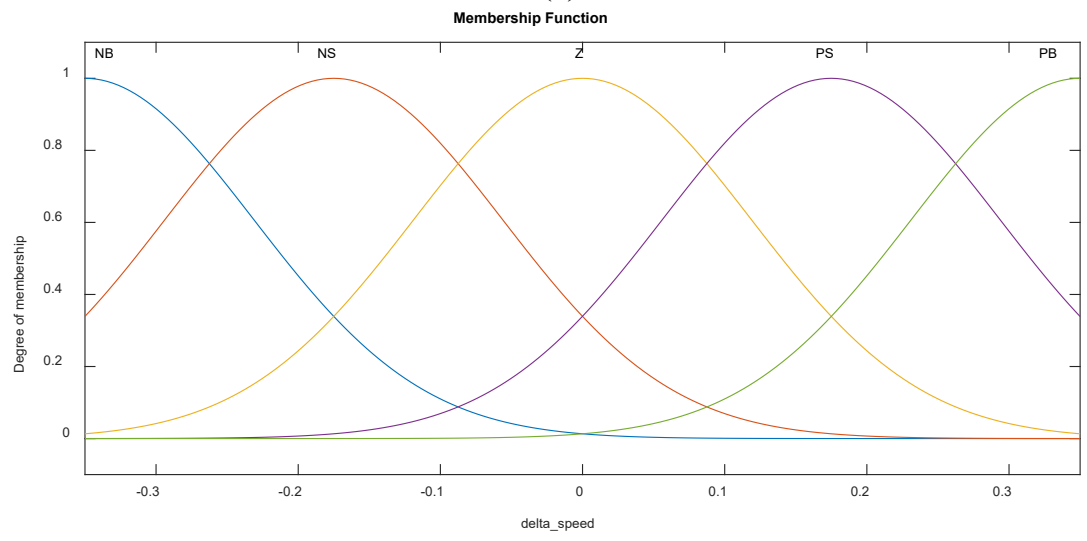

(b)

Figure 11. (a) Error (slip) and (b) delta speed (relative velocity) membership function.

SFPID controller rules for $k_{p}, k_{i}$, and $k_{d}$ parameters are shown in Table 4. The controller rules, like those of FPID controllers, are established and tuned on a regular basis based on the direct knowledge and abilities of specialists in response to error and delta speed variations. This controller's control rules also produce a crisp output, as illustrated by the overall defuzzification results in Figure 12(a) to 12(c). On a three-dimensional surface, these figures depict the relationship between the error and delta speed inputs and the $k_{p} / k_{i} / k_{d}$ output. As can be seen, the singleton range of output fuzzy variables were 200 to 800 for $k_{p}, 10$ to 30 for $k_{i}$, and 10 to 40 for $k_{d}$. 
Table 4. Rules of SFPID controller.

\begin{tabular}{ccccccc}
\hline \multirow{2}{*}{$k_{p} / k_{i} / k_{d}$} & \multicolumn{7}{c}{ Delta speed } & PB \\
\hline \multirow{4}{*}{ error } & $\mathrm{NB}$ & $\mathrm{PB} / \mathrm{NB} / \mathrm{Z}$ & $\mathrm{Z} / \mathrm{NS} / \mathrm{PB}$ & $\mathrm{NS} / \mathrm{PB} / \mathrm{NB}$ & $\mathrm{NB} / \mathrm{Z} / \mathrm{PS}$ & $\mathrm{PS} / \mathrm{PS} / \mathrm{NS}$ \\
& $\mathrm{NS}$ & $\mathrm{PS} / \mathrm{NS} / \mathrm{NS}$ & $\mathrm{PB} / \mathrm{NB} / \mathrm{Z}$ & $\mathrm{NB} / \mathrm{PS} / \mathrm{PB}$ & $\mathrm{Z} / \mathrm{PB} / \mathrm{NB}$ & $\mathrm{NS} / \mathrm{Z} / \mathrm{PS}$ \\
& $\mathrm{Z}$ & $\mathrm{Z} / \mathrm{PB} / \mathrm{PS}$ & $\mathrm{PS} / \mathrm{PS} / \mathrm{NB}$ & $\mathrm{PB} / \mathrm{Z} / \mathrm{NS}$ & $\mathrm{NS} / \mathrm{NB} / \mathrm{PB}$ & $\mathrm{NB} / \mathrm{NS} / \mathrm{Z}$ \\
& $\mathrm{PS}$ & $\mathrm{NS} / \mathrm{Z} / \mathrm{NB}$ & $\mathrm{NB} / \mathrm{PB} / \mathrm{NS}$ & $\mathrm{Z} / \mathrm{NS} / \mathrm{PS}$ & $\mathrm{PS} / \mathrm{PS} / \mathrm{Z}$ & $\mathrm{PB} / \mathrm{NB} / \mathrm{PB}$ \\
& $\mathrm{PB}$ & $\mathrm{NB} / \mathrm{PS} / \mathrm{PB}$ & $\mathrm{NS} / \mathrm{Z} / \mathrm{PS}$ & $\mathrm{PS} / \mathrm{NB} / \mathrm{Z}$ & $\mathrm{PB} / \mathrm{NS} / \mathrm{NS}$ & $\mathrm{Z} / \mathrm{PB} / \mathrm{NB}$ \\
\hline
\end{tabular}

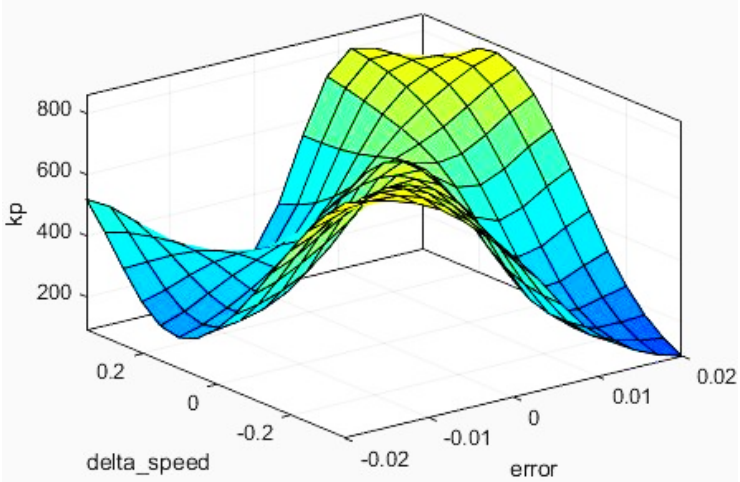

(a) $k_{p}$.

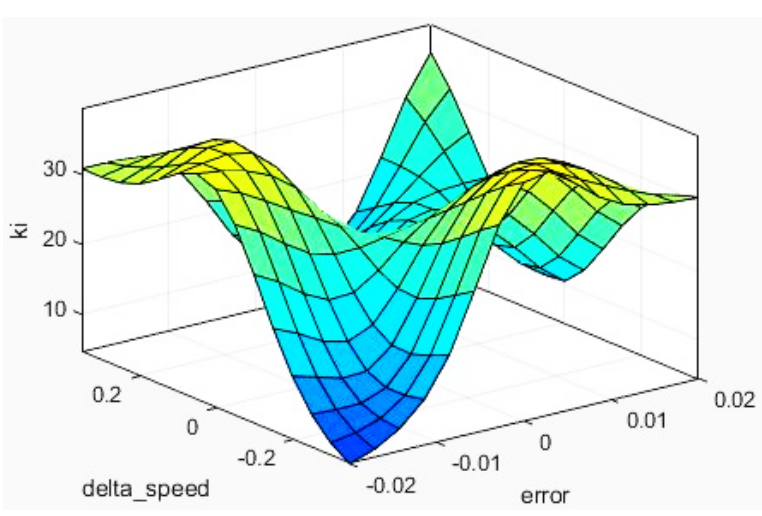

(b) $k_{i}$.

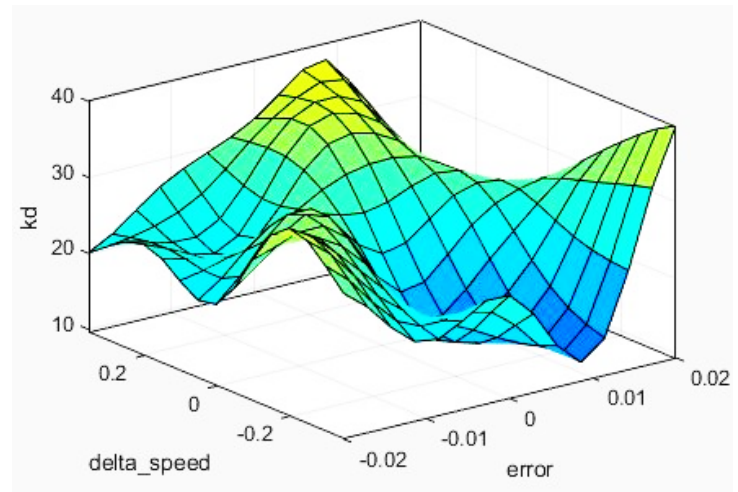

(c) $k_{d}$

Figure 12. Defuzzification outputs.

\section{PERFORMANCE OF THE PROPOSED ANTILOCKING BRAKING SYSTEM CONTROL STRUCTURE}

To evaluate the performance of the proposed SFPID controller, the previous control structure, fuzzy fractional PID controller developed by Ahmad et al. [4] is used as a benchmark. The test is carried out by simulating speeds of 40, 60, and $90 \mathrm{~km} / \mathrm{h}$. These speeds were chosen in accordance with the Malaysia Road Transport Act (1987), which specifies a speed limit of $40 \mathrm{~km} / \mathrm{h}$ for residential zones, $60 \mathrm{~km} / \mathrm{h}$ for urban areas, and $90 \mathrm{~km} / \mathrm{h}$ for federal highways. Several features, including relative velocity between the vehicle and the wheel, longitudinal tire travel, and stopping distance travelled by the vehicle, have been studied and compared with other controllers, such as PID and FPID. Furthermore, the assessment is carried out in order to archive the desired slip of $0.2,0.4,0.6$, and 0.8 . Typically, in ABS research, the target longitudinal slip is set at 0.2 to provide optimal braking performance without skidding, but this study examined different desired longitudinal slip values to examine brake performance across a range of road surface conditions, like snow, wet asphalt, and dry concrete.

Figures 13 and 14 depict the evaluation at a speed of $40 \mathrm{~km} / \mathrm{h}$. During the simulation, sudden braking is applied after 1 second of vehicle travel. In terms of relative velocity between the vehicle and the wheel and slip, the SFPID controller outperforms the FPID and PID controllers. SFPID requires $1.196 \mathrm{~s}$ to archive zero velocity for a slip of 0.2 , whereas FPID requires $1.201 \mathrm{~s}$ and PID requires $1.416 \mathrm{~s}$. The same pattern can be predicted for slip value of 0.4 whereby SFPID $=1.294$ $\mathrm{s}, \mathrm{FPID}=1.287 \mathrm{~s}$ and PID $=1.292 \mathrm{~s}$, slip $0.6 \mathrm{SFPID}=1.421 \mathrm{~s}$, FPID $=1.424 \mathrm{~s}$ and PID $1.43 \mathrm{~s}$, and slip 0.8, SFPID $=$ $1.544 \mathrm{~s}, \mathrm{FPID}=1.572 \mathrm{~s}$ and PID $=1.619 \mathrm{~s}$, respectively. When compared to FPID and PID, SFPID effectively improves braking stability by preventing jerking during braking, as shown in Figure 13(c), 13(f), 14(c) and 14(f), where the SFPID has a faster response to approaching the steady-state condition. While SFPID in longitudinal slip reveals that it has a relatively overdamp behaviour when compared to FPID, the SFPID still has a better condition to archive faster settling time. The effectiveness of SFPID can also be seen in the stopping distance condition. Among the other controllers, the SFPID has the shortest stop distance in slip 0.8, $0.12 \mathrm{~m}$ less than the FPID and $0.38 \mathrm{~m}$ less than the PID. SFPID's stopping 
distances are between FPID and PID in slips 0.2,0.4, and 0.6, but the values are still within acceptable limits. As a result, in the range of $0.01 \mathrm{~m}$ to $0.02 \mathrm{~m}$, the stopping distances are slightly longer than the FPID and slightly better than the PID in the range of $0.02 \mathrm{~m}$ to $1.4 \mathrm{~m}$.

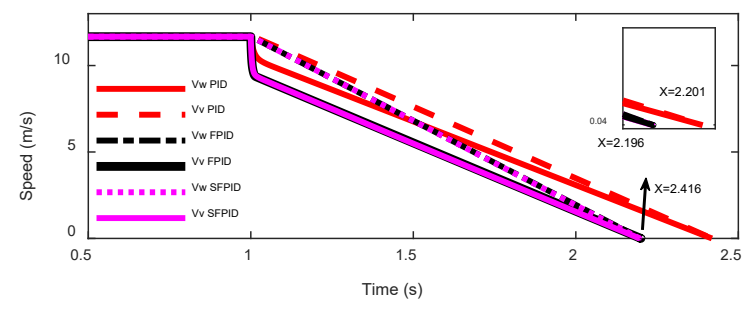

(a)

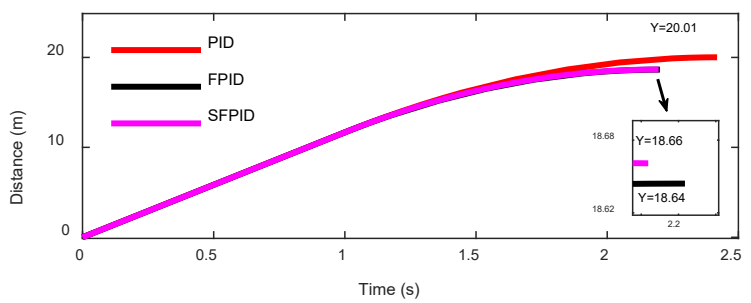

(b)

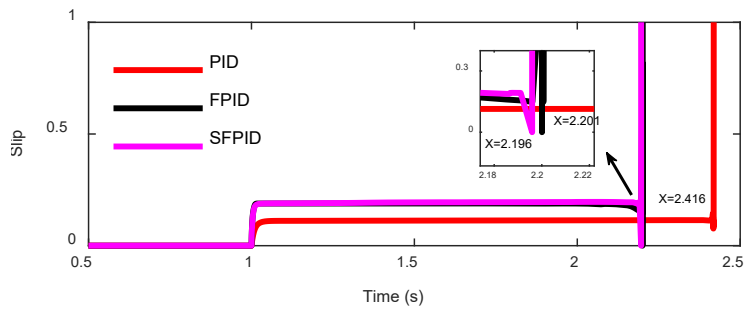

(c)

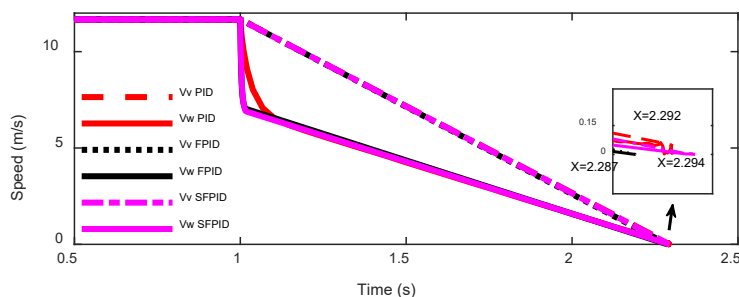

(d)

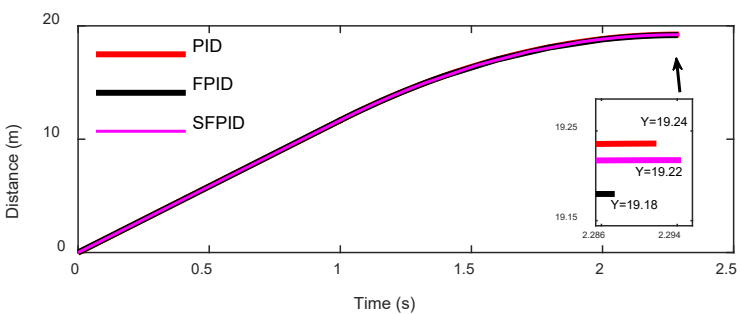

(e)

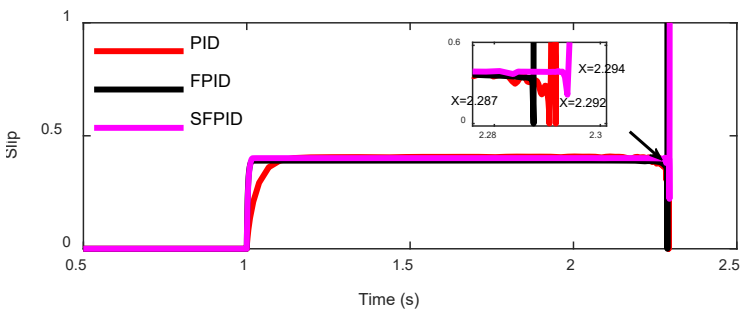

(f)

Figure 13. Responses of the proposed controller at speed $40 \mathrm{~km} / \mathrm{h}$ for (a),(b),(c) targeted slip 0.2 and (d),(e),(f) targeted slip 0.4 .

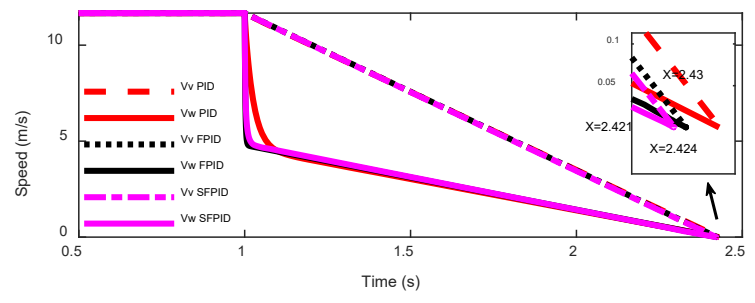

(a)

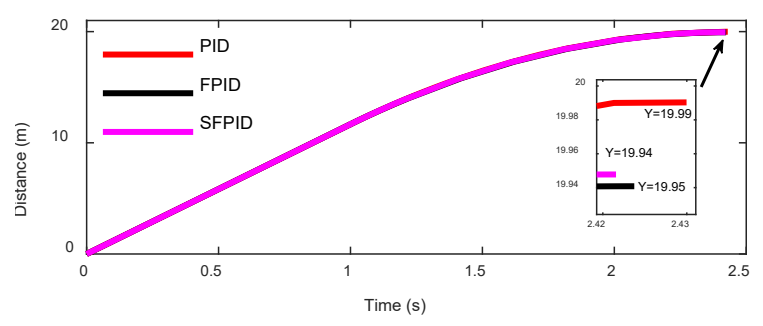

(b)

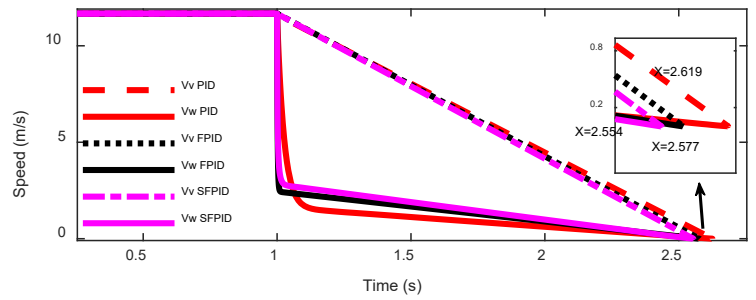

(d)

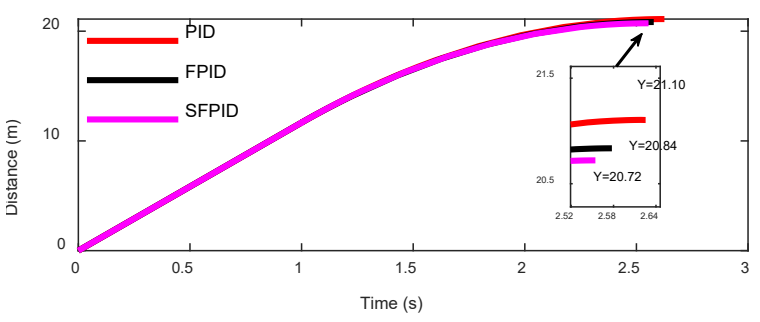

(e) 


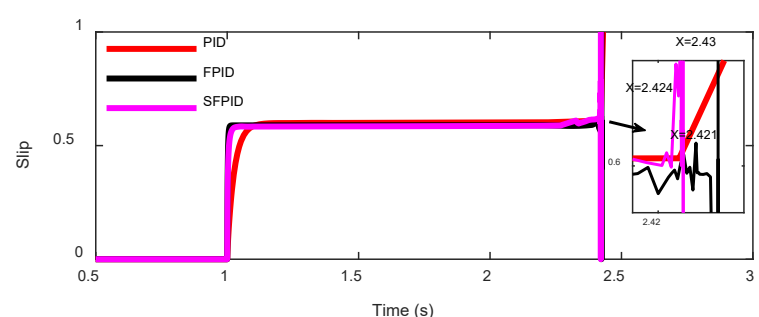

(c)

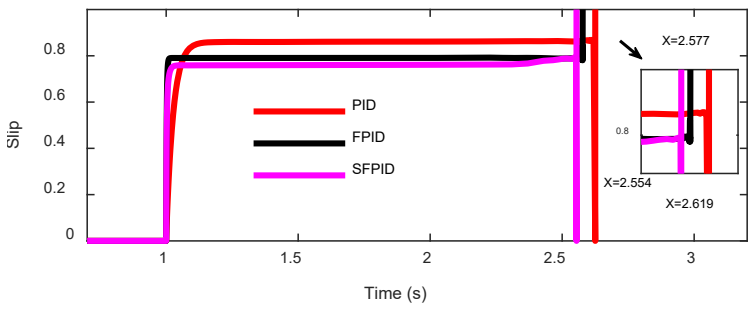

(f)

Figure 14. Responses of the proposed controller at speed $40 \mathrm{~km} / \mathrm{h}$ for (a),(b),(c) targeted slip 0.6 and

(d),(e),(f) targeted slip 0.8 .

The evaluation was continued at $60 \mathrm{~km} / \mathrm{h}$ speed, as shown in Figure 15 and 16, with target slips of 0.2, 0.4, 0.6, and 0.8. According to the figures, the SFPID controller can achieve acceptable control performance when compared to the FPID and PID controllers with the fastest zero-reach speed. According to all slip conditions, the SFPID outperforms the others in that in the targeted slip 0.2 , the SFPID requires $1.708 \mathrm{~s}$ to completely stop compared to the PID $=1.715 \mathrm{~s}$ and the PID $=1.739 \mathrm{~s}$. SFPID gives $1.848 \mathrm{~s}$ to stop in the 0.4 targeted slip, which is a quiet delay when compared to FPID $=$ $1.837 \mathrm{~s}$ and PID $=1.847 \mathrm{~s}$. This is due to a slight excess of SFPID, which causes the settlement time to archive a stable state to be delayed. This problem would be solved by fine-tuning the SFPID controller. With slips of 0.6 and 0.8 , SFPID performance improves. The results show that SFPID takes time $1.996 \mathrm{~s}$ to stop during $0.6 \mathrm{slip}$, compared to $2.033 \mathrm{~s}$ for FPID and $2.043 \mathrm{~s}$ for PID, and that SFPID requires $0.034 \mathrm{~s}$ faster than FPID and $0.09 \mathrm{~s}$ less faster PID controllers in 0.8 slip. SFPID has the outstanding performance in slip 0.2, 0.6 , and 0.8 when compared to others, but it has a much longer stopping distance, $0.09 \mathrm{~m}$ longer than FPID but $0.06 \mathrm{~m}$ shorter than PID controllers. The SFPID has a stopping distance of $30.92 \mathrm{~m}$ in a slip of 0.2 , compared to $30.98 \mathrm{~m}$ for the FPID and $31.18 \mathrm{~m}$ for the PID. The results of SFPID $=33.27 \mathrm{~m}$, FPID $=33.61 \mathrm{~m}$, and PID $=33.65 \mathrm{~m}$ are shown in slip 0.6, while SFPID gets the best result in slip $0.8,0.34 \mathrm{~m}$ shorter than FPID, and PID controller is the worst at $35.9 \mathrm{~m}$. SFPID demonstrated superior slip control in all expected slips except 0.4 slip. When compared to FPID and PID controllers, SFPID results show less jerking when reaching the stable state condition. This is because SFPID has a faster settling time event, despite having a slightly overdamped condition when compared to FPID. The opposite is true for slip 0.4, where slip monitoring indicates a relatively late settling time due to minor overshoot when compared to FPID and PID controllers, but the jerking is still less than with others.

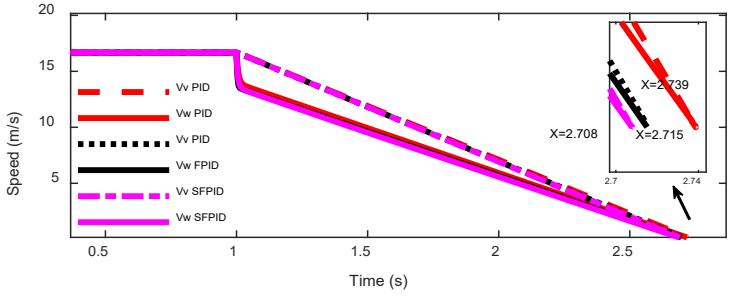

(a)

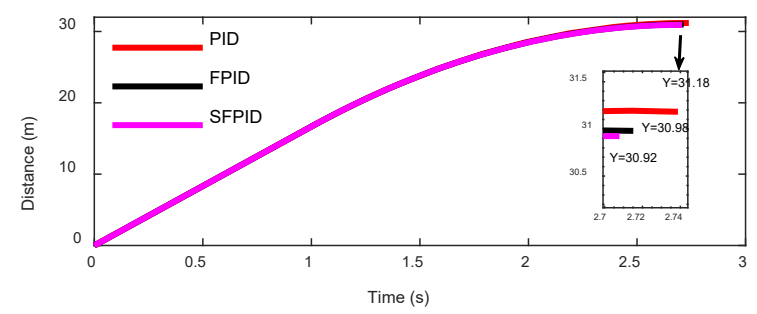

(b)

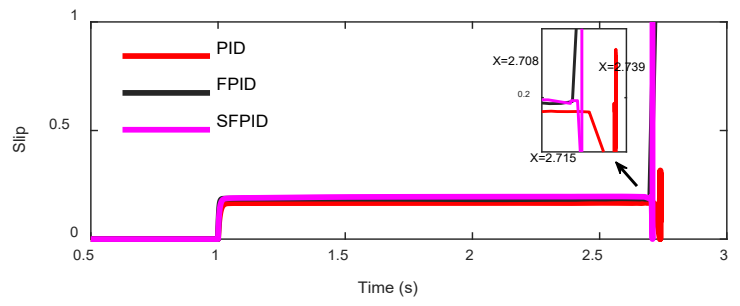

(c)

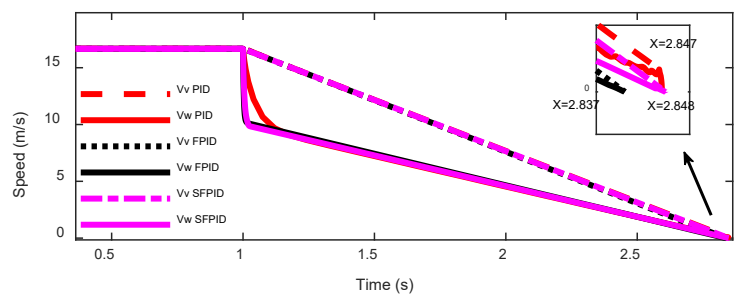

(d)

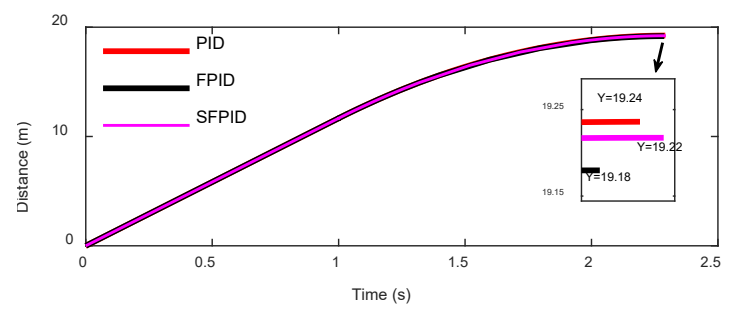

(e)

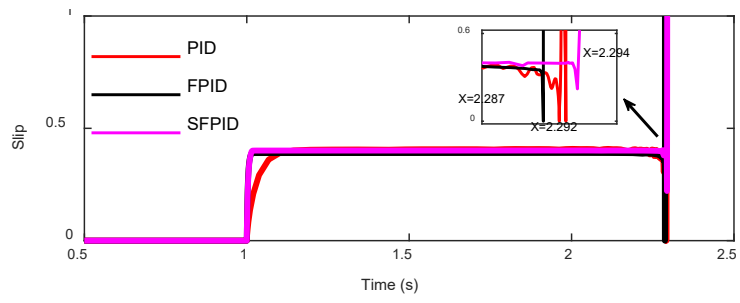

(f)

Figure 15. Responses of the proposed controller at speed $60 \mathrm{~km} / \mathrm{h}$ for (a),(b),(c) targeted slip 0.2 and (d),(e),(f) targeted slip 0.4 . 


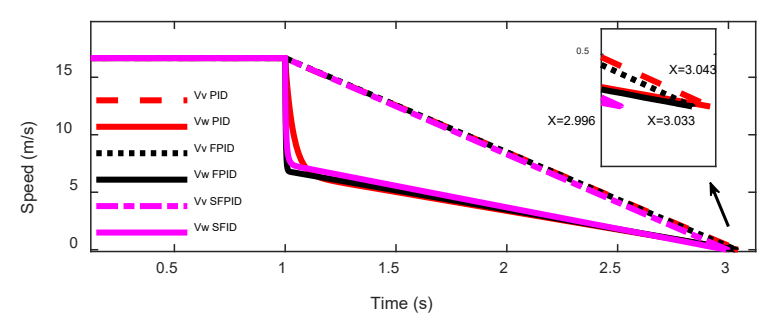

(a)

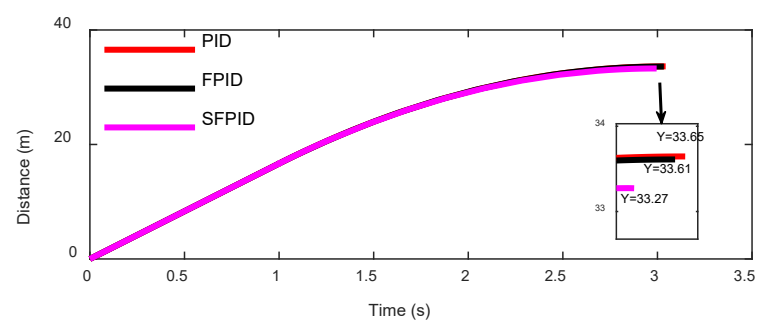

(b)

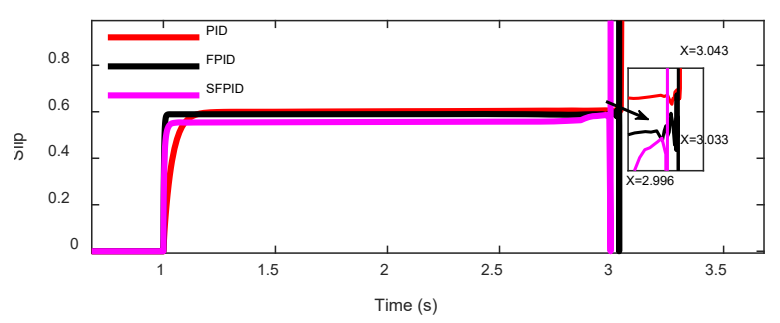

(c)

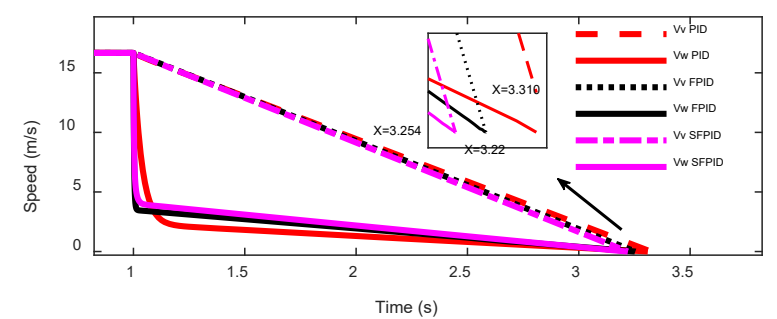

(d)

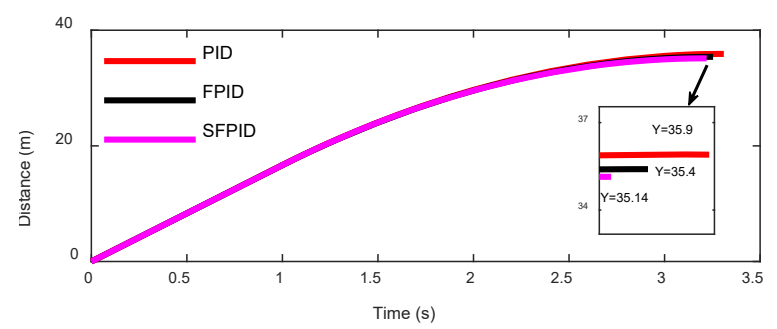

(e)

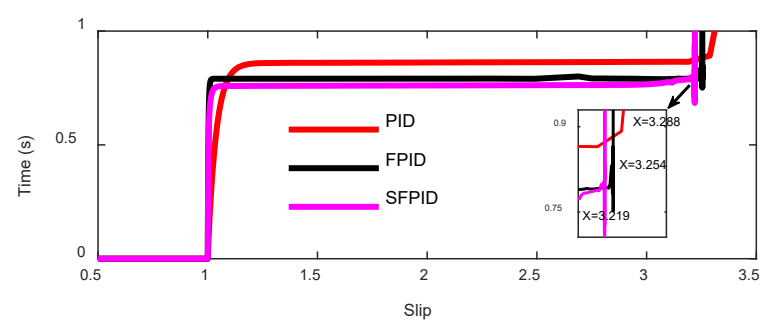

(f)

Figure 1 Responses of the proposed controller at speed $60 \mathrm{~km} / \mathrm{h}$ for (a),(b),(c) targeted slip 0.6 and (d),(e),(f) targeted slip 0.8 .

To evaluate the proposed controller's effectiveness in providing a reasonable tracking slip, vehicle velocities are increased to up to $90 \mathrm{~km} / \mathrm{h}$ for each targeted slip by $0.2,0.4,0.6$, and 0.8 , as shown in Figure 17 to Figure 18 . Despite changes in speed and targeted slip, the SFPID controller can still approach the targeted slip with a faster settling time and less jerking than the FPID and PID controllers. Furthermore, the results of the relative velocity between vehicle speed and wheel speed for each targeted slip showed that SFPID has the best stop time, which could be reached by SFPID at slip 0.2 is $2.560 \mathrm{~s}$ compared to FPID $=2.572 \mathrm{~s}$ and PID $=3.014 \mathrm{~s}$. For slip 0.4 , SFPID $=2.754 \mathrm{~s}$, FPID $=2.756 \mathrm{~s}$ and PID $=2.778 \mathrm{~s}$. SFPID also performed better in slip 0.6, with a stop time of $3.006 \mathrm{~s}$ compared to FPID $=3.051 \mathrm{~s}$ and PID $=$ $3.067 \mathrm{~s}$. Finally, in slip 0.8 , the SFPID controller has a $0.036 \mathrm{~s}$ faster stop time than the FPID controller and $0.141 \mathrm{~s}$ faster than the PID controller. Meanwhile, the SFPID controller indicates that the vehicle can stop within the minimum stopping distance from the other control structure in terms of distance travelled. In comparison with FPID $=57.13 \mathrm{~m}$ and PID = $64,09 \mathrm{~m}$, the distance travelling by the controller is approximately $57.05 \mathrm{~m}$ for a targeted slip of 0.2 . The stopping distance for SFPID $=59.37 \mathrm{~m}$, FPID $=59.46 \mathrm{~m}$ and PID $=59.77 \mathrm{~m}$ in a targeted slip of 0.4 . Furthermore, the SFPID controller achieves $62.62 \mathrm{~m}$ of stopping distance travel for slip 0.6, whereas the FPID controller achieves $63.13 \mathrm{~m}$ and the PID controller achieves $63.30 \mathrm{~m}$. Nonetheless, with a targeted slip of 0.8 , the distance travelled to stop by the vehicle is about $66.72 \mathrm{~m}$ better than FPID, which is nearly $67.23 \mathrm{~m}$, and the worst distance is approximately $68.32 \mathrm{~m}$ by PID controller.

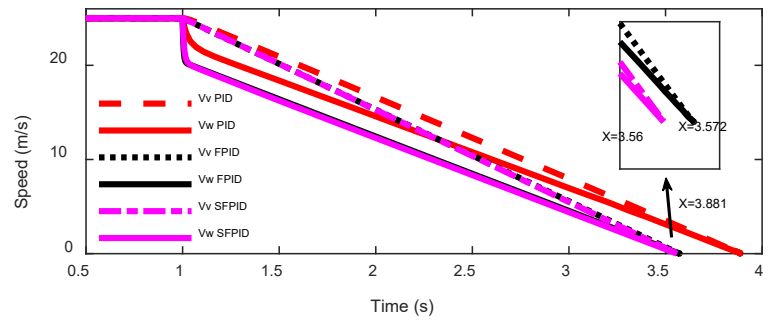

(a)

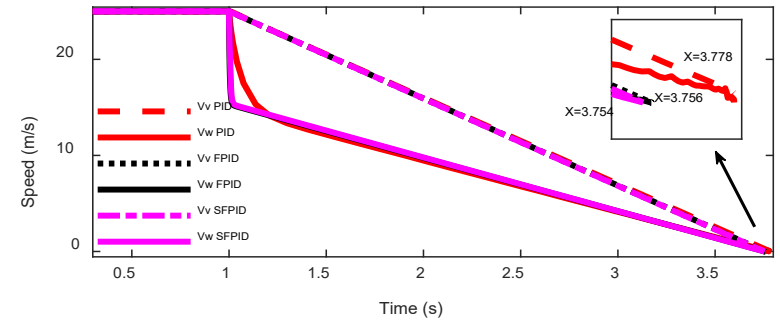

(d) 


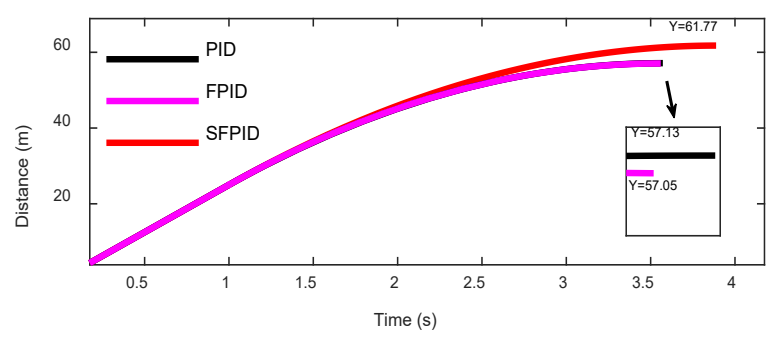

(b)

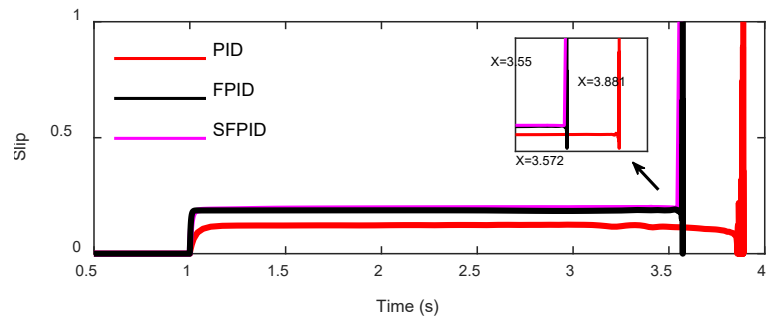

(c)

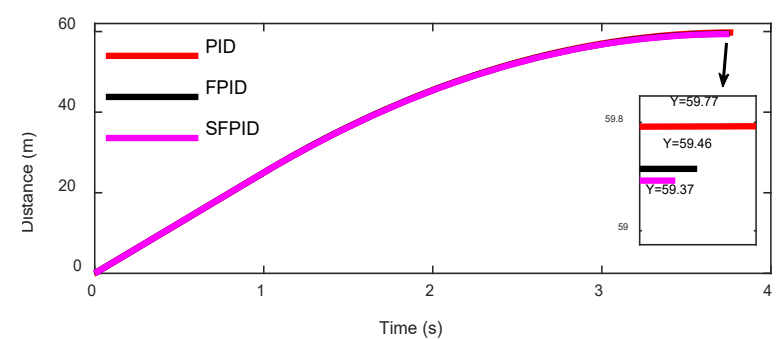

(e)

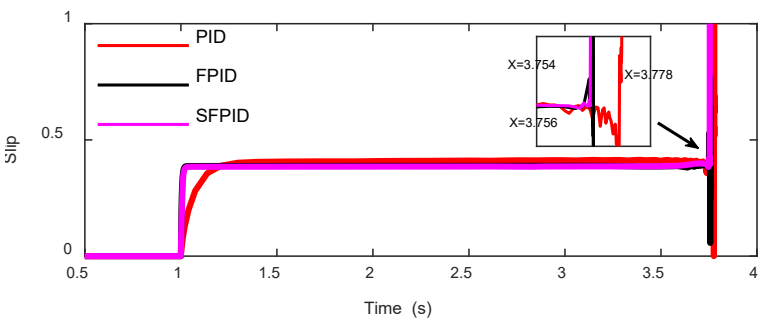

(f)

Figure 17. Responses of the proposed controller at speed $90 \mathrm{~km} / \mathrm{h}$ for (a),(b),(c) targeted slip 0.2 and (d),(e),(f) targeted slip 0.4.

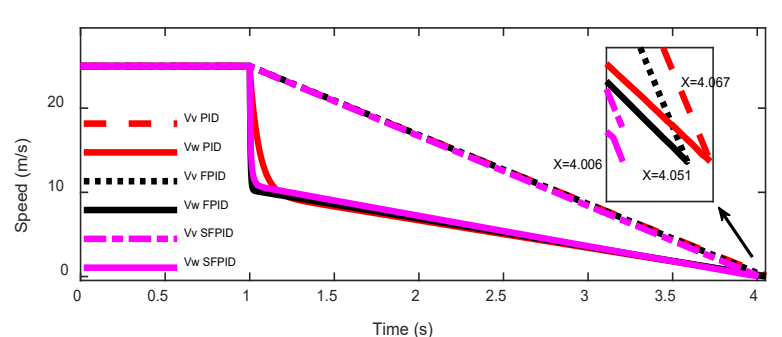

(a)

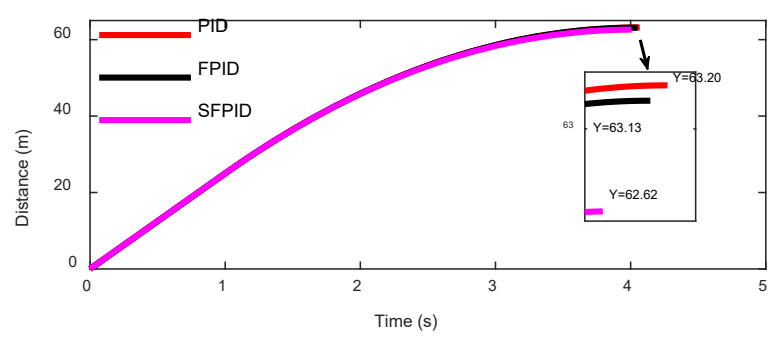

(b)

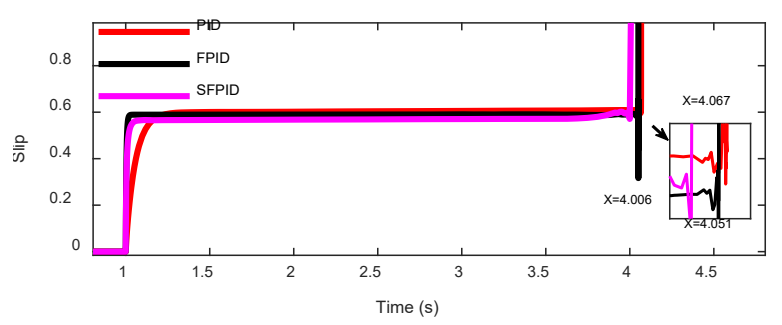

(c)

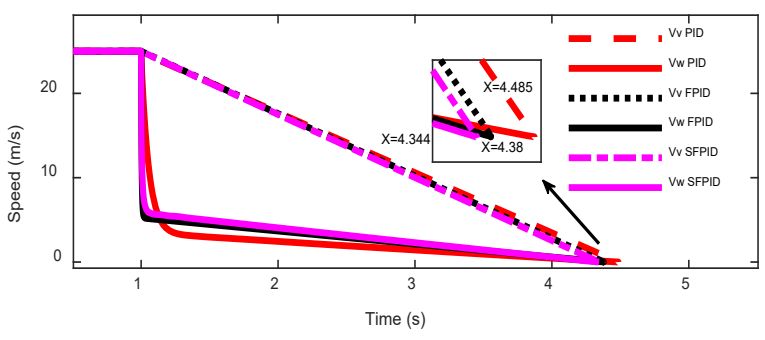

(d)

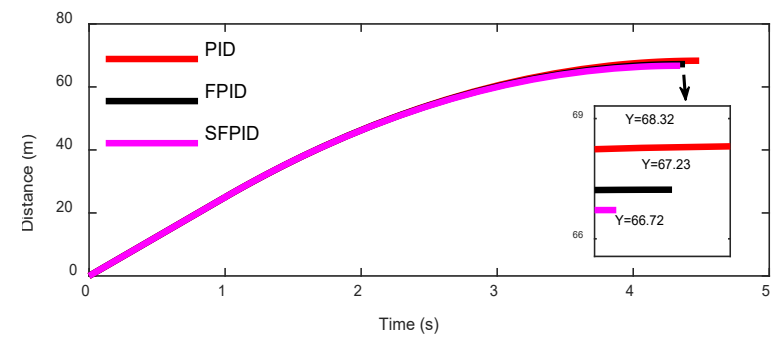

(e)

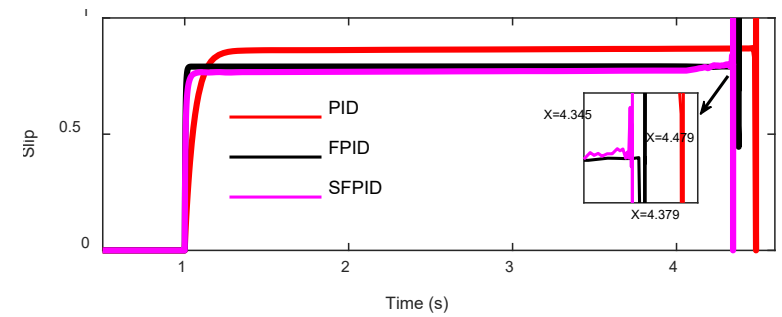

(f)

Figure 18. Responses of the Proposed Controller at Speed $90 \mathrm{~km} / \mathrm{h}$ for (a),(b),(c) targeted slip 0.6 and (d),(e),(f) targeted slip 0.8 .

Table 5 summarises the values obtained from the assessments performed at each speed and the target slip previously plotted on each graph. 
Table 5: Comparison of the values of stopping time, stopping distance and longitudinal slip for each controller.

\begin{tabular}{|c|c|c|c|c|c|}
\hline Velocity $(\mathrm{km} / \mathrm{h})$ & Slip & Controller & Stopping time (s) & Stopping distance (m) & Longitudinal slip \\
\hline \multirow{12}{*}{40} & \multirow{3}{*}{0.2} & PID & 2.416 & 20.01 & 0.122 \\
\hline & & FPID & 2.201 & 18.64 & 0.182 \\
\hline & & SFPID & 2.194 & 18.66 & 0.196 \\
\hline & \multirow{3}{*}{0.4} & PID & 2.294 & 19.24 & 0.411 \\
\hline & & FPID & 2.287 & 19.18 & 0.388 \\
\hline & & SFPID & 2.292 & 19.22 & 0.386 \\
\hline & \multirow{3}{*}{0.6} & PID & 2.430 & 19.99 & 0.601 \\
\hline & & FPID & 2.424 & 19.94 & 0.589 \\
\hline & & SFPID & 2.421 & 19.95 & 0.585 \\
\hline & \multirow{3}{*}{0.8} & PID & 2.619 & 21.10 & 0.861 \\
\hline & & FPID & 2.577 & 20.84 & 0.791 \\
\hline & & SFPID & 2.554 & 20.72 & 0.760 \\
\hline \multirow{12}{*}{60} & \multirow{3}{*}{0.2} & PID & 2.739 & 31.18 & 0.166 \\
\hline & & FPID & 2.715 & 30.98 & 0.186 \\
\hline & & SFPID & 2.708 & 30.92 & 0.195 \\
\hline & \multirow{3}{*}{0.4} & PID & 2.847 & 32.12 & 0.408 \\
\hline & & FPID & 2.387 & 31.97 & 0.388 \\
\hline & & SFPID & 2.848 & 32.06 & 0.401 \\
\hline & \multirow{3}{*}{0.6} & PID & 3.043 & 33.65 & 0.602 \\
\hline & & FPID & 3.033 & 33.61 & 0.589 \\
\hline & & SFPID & 2.996 & 33.27 & 0.555 \\
\hline & \multirow{3}{*}{0.8} & PID & 3.310 & 35.90 & 0.861 \\
\hline & & FPID & 3.254 & 35.40 & 0.791 \\
\hline & & SFPID & 3.220 & 35.14 & 0.761 \\
\hline \multirow{12}{*}{90} & \multirow{3}{*}{0.2} & PID & 3.881 & 61.77 & 0.124 \\
\hline & & FPID & 3.572 & 57.13 & 0.187 \\
\hline & & SFPID & 3.560 & 57.05 & 0.196 \\
\hline & \multirow{3}{*}{0.4} & PID & 3.778 & 59.77 & 0.411 \\
\hline & & FPID & 3.756 & 59.46 & 0.388 \\
\hline & & SFPID & 3.754 & 59.37 & 0.385 \\
\hline & \multirow{3}{*}{0.6} & PID & 4.607 & 63.20 & 0.604 \\
\hline & & FPID & 4.051 & 63.13 & 0.590 \\
\hline & & SFPID & 4.006 & 62.62 & 0.569 \\
\hline & \multirow{3}{*}{0.8} & PID & 4.485 & 68.32 & 0.864 \\
\hline & & FPID & 4.380 & 67.23 & 0.791 \\
\hline & & SFPID & 4.344 & 66.72 & 0.771 \\
\hline
\end{tabular}

\section{CONCLUSION}

This study proposed an ABS control mechanism centred on the EWB system. The control mechanism is developed through the self-tuning PID control system by two control structures: fuzzy PID (FPID) and self-tuning fuzzy PID (SFPID). The difference between these two control structures lies in the fuzzy logic input used. The SFPID performance is then compared with the traditional PID controller and the FPID controller to determine which controller is more effective. The primary goal of this research is to calculate the output of an ABS-EWB controller in terms of longitudinal slip, the relative speed between vehicle and wheel, and vehicle stopping distance. To manage and test the effectiveness of the developed controllers, a validated quarter car model was used as the target system. Several speeds of $40 \mathrm{~km} / \mathrm{h}, 60$ $\mathrm{km} / \mathrm{h}$, and $90 \mathrm{~km} / \mathrm{h}$ are attempted, with slip targets of $0.2,0.4,0.6$, and 0.8 . The findings revealed that the proposed SFPID control technique effectively controlled the ABS by reviewing the responses of the SFPID structure to other FPID controller and conventional PID controller results. The performance of SFPID demonstrates this, as it is $10 \%$ and $1 \%$ faster in terms of stopping time and $8 \%$ and $1 \%$ shorter in terms of stopping distance than PID and FPID, respectively. Furthermore, SFPID has a faster time settlement than PID and FPID, with 9\% and 1\%, respectively, and is more effective in achieving the target slip of $40 \%$ and $5 \%$, in both, than PID and FPID.

In comparison to other controllers, overall performance reveals that the SFPID controller can approach reasonable slip tracking with the fastest stoppage, fastest settling time, shortest stopping distance, and ability to attain a steady-state position soon. Finally, the SFPID controller could be used as a control method in an ABS. Furthermore, by combining it with another smart controller, the existing control system may be improved to allow it to be used on genuine EWB test rigs for future development. 


\section{ACKNOWLEDGEMENT}

The authors would like to thank UTeM for funding this work under an internal grant PJP/2020/FKM/PP/S01783.

\section{REFERENCES}

[1] F. Ahmad et al., "Simulation and experimental investigation of vehicle braking system employing a fixed caliper based electronic wedge brake," Simulation, vol. 94, no. 4, pp. 327-340, 2018, doi: 10.1177/0037549717733805.

[2] F. Ahmad et al., "Modelling, validation and adaptive PID control with pitch moment rejection of active suspension system for reducing unwanted vehicle motion in longitudinal direction," Int. J. Veh. Syst. Model. Test., vol. 5, no. 4, pp. 312-346, 2010, doi: 10.1504/IJVSMT.2010.038036.

[3] F. Ahmad et al., "Modelling and control of a fixed calliper-based electronic wedge brake," Stroj. Vestn. / J. Mech. Eng., vol. 63, no. 3, pp. 181-190, 2017, doi: 10.5545/sv-jme.2016.3508.

[4] F. Ahmad et al., "Fuzzy fractional PID gain controller for antilock braking system using an electronic wedge brake mechanism," Int. J. Veh. Saf., vol. 10, no. 2, pp. 97, 2018, doi: 10.1504/IJVS.2018.094154.

[5] A. Aksjonov et al., "Hardware-in-the-loop test of an open loop fuzzy control method for decoupled electro-hydraulic antilock braking system," IEEE Trans Fuzzy Syst., vol. 9, no. 5, pp. 965-975, 2020, doi: 10.1109/TFUZZ.2020.2965868.

[6] A. Aksjonov et al., "Trajectory phase-plane method - based analysis of stability and performance of a fuzzy logic controller for an anti-lock braking system," In IEEE International Conference on Mechatronics, 2019, pp. 602-607, doi: 10.1109/ICMECH.2019.8722831.

[7] A. Aksjonov, V. Vodovozov, and Z. Raud, "Improving energy recovery in blended antilock braking systems of electric vehicles," In IEEE 16th International Conference on Industrial Informatics, 2018, pp. 589-594, doi: 10.1109/INDIN.2018.8472024.

[8] BA. Alkharasani et al., "PID-sliding surface based sliding mode controller for anti-lock braking system of electric vehicle," Adv. Sci. Lett., vol. 22, no. 10, pp. 2734-2737, 2016, doi: 10.1166/asl.2016.7016.

[9] V.R. Aparow et al., "Development of antilock braking system based on various intelligent control system," Appl. Mech. Mater., vol. 229-231, pp. 2394-2398, 2014, doi: 10.4028/www.scientific.net/AMM.229-231.2394.

[10] V.R. Aparow et al., "Modelling and PID control of antilock braking system with wheel slip reduction to improve braking performance," Int. J. Veh. Saf., vol. 6, no. 3, pp. 265-296, 2013, doi: 10.1504/IJVS.2013.055025.

[11] V.R. Aparow et al., "Identification of intelligent controls in developing anti-lock braking system," J. Adv. Manuf. Technol., Vol. 7, No. 1, pp. 1-14, 2014.

[12] K.P. Babu, "ANN based controller for anti-locking braking system," International Journal of Innovative Technology and Exploring Engineering, vol. 8, no. 6S4, 2019, doi: 10.35940/ijitee.F1091.0486S419.

[13] W. Batayneh, M. Jaradat, and A. Bataineh, "Intelligent adaptive control for anti-lock braking system," In ASME Int. Mech. Eng. Congress Expos. Proc., 2018, pp. 1-13, doi: 10.1115/IMECE2018-87659.

[14] F. Betin, D. Pinchon, and GA. Capolino, "A time-varying sliding surface for robust position control of a DC motor drive," IEEE Trans. Ind. Electron., vol. 49, no. 2, 2002, doi: 10.1109/41.993280.

[15] C.E. Castañeda et al., "Position control of DC motor based on recurrent high order neural networks," In IEEE International Symposium on Intelligent Control, 2010, pp.1515-1520, doi: 10.1109/ISIC.2010.5612932.

[16] P. Chaudhari et al., "Disturbance observer based sliding mode control for anti-lock braking system," In 1st IEEE International Conference on Power Electronics, Intelligent Control and Energy Systems, 2016, pp. 1-5, doi: 10.1109/ICPEICES.2016.7853488.

[17] M.H. Che Hasan et al., "Modelling and design of optimised electronic wedge brake," In 2019 IEEE International Conference on Automatic Control and Intelligent System, 2019, pp. 189-193, doi: 10.1109/I2CACIS.2019.8825045.

[18] JS Cheon, "Brake by wire system configuration and functions using front EWB (Electric Wedge Brake) and rear EMB (ElectroMechanical Brake) actuators," SAE Technical Papers paper no. 1, 2010, doi: 10.4271/2010-01-1708.

[19] V. Dankan Gowda et al. "Modelling and performance evaluation of anti-lock braking system," J. Eng. Sci. Technol., vol. 14, no. 5, pp. 3028-3045, 2019.

[20] A. Deshmukh, PD. Shendge, and SB. Phadke, "Effect of Second order actuator on performance of anti-lock braking system with multiple sliding surface," In: Proceedings of the 2nd International Conference on Intelligent Computing and Control Systems, 2018, pp. 313-317.

[21] E. Dong, and L. Zhang, "Vehicle stability control system of emergency brake on split-mu road," In 9th International Conference on Intelligent Human-Machine Systems and Cybernetics, 2017, pp. 252-255, doi: 10.1109/IHMSC.2017.65.

[22] A. Ghajari, and R. Kazemi, "A new approach to the electronic wedge brake," SAE Technical Papers: 7; 2012.

[23] S. Hamamci et al., "Design of a multiple-model switching controller for ABS braking dynamics," Trans. Inst. Meas. Control., vol. 37, no. 5, 2015, doi: 10.1177/0142331214546522.

[24] SI. Haris, "Modelling and validation of quarter vehicle traction model," In SA Conference Series: Industrial Revolution 4.0, 1(01), 2020, pp. 65-73..

[25] Y. He et al., "Design and analysis of output feedback constraint control for antilock braking system based on Burckhardt's mode," Assembly Automation, vol. 39, no. 4, pp. 497-513, 2019, doi: 10.1108/AA-08-2018-0119.

[26] Y. He et al., "A second-order slip model for constraint backstepping control of antilock braking system based on Burckhardt's model," Int. J. Model. Simul., vol. 40, no. 1, pp. 1-13, 2020, doi: 10.1080/02286203.2019.1570449.

[27] LM Ho et al., "The electronic wedge brake - EWB," SAE Technical Paper 2006-01-3196, 2006.

[28] K. Hudha, "Non-parametric modelling and modified hybrid skyhook groundhook control of magnetorheological dampers for automotive suspension system," Universiti Teknologi Malaysia, Johor, 2005.

[29] K. Hudha et al., "Modelling, validation and roll moment rejection control of pneumatically actuated active roll control for improving vehicle lateral dynamics performance," Int. J. Eng. Syst. Model. Simul., vol. 1, no. 2/3, 2009, doi: 10.1504/IJESMS.2009.027576.

[30] J.G. Kim et al., "Developing of electronic wedge brake with cross wedge," SAE Technical Paper: 2009-01-0856, 2009, doi: 10.4271/2009-01-0856. 
[31] J.G. Kim et al., "ABS / ESC / EPB control of electronic wedge brake,” SAE Technical Paper: 2010-01-0074, 2010, doi: 10.4271/2010-01-0074.

[32] V.T. Minh et al., "Development of anti-lock braking system (ABS) for vehicles braking," Open Engineering, vol. 6, no. 1, pp. 554-559, 2016, doi: 10.1515/eng-2016-0078.

[33] M. Moavenian, and NS. Sadeghi, "An adaptive modified fuzzy-sliding mode longitudinal control design and simulation for vehicles equipped with ABS system," Int. J. Automot. Eng., vol. 9, no. 1, pp. 2895-2907, 2019, doi: 10.22068/ijae.9.1.2895.

[34] M. Mokarram, A. Khoei, and K. Hadidi, "A fuzzy Anti-lock braking system (ABS) controller using CMOS circuits," Microprocessors and Microsystems, vol. 70, pp. 47-52, 2019, doi: 10.1016/j.micpro.2019.05.001.

[35] H.R. More, A.A. Digrase, and A.V. Wayse, "Linear PID control technique for single wheel ABS (anti-lock braking system) of motorcycle," In 2nd International Conference for Convergence in Technology, 2017, pp. 277-281, doi: 10.1109/I2CT.2017.8226135.

[36] M. Sahin, and YS. Ünlüsoy, "Design and simulation of an ABS for an integrated active safety system for road vehicles," Int. J. Veh. Des., vol. 52, no. 1-4, pp. 64-81, 2010, doi: 10.1504/IJVD.2010.029636.

[37] Á. Semsey, and R. Roberts, "Simulation in the development of the electronic wedge brake," SAE Technical Papers: $724,2006$.

[38] M. Soomro, M.K. Hassan, and F. Ahmad, "Modelling and validation of an electronic wedge brake system with realistic Quarter Car Model for anti-lock braking system design," Int. J. Integr. Eng., vol. 11, no. 4, pp. 70-80, 2019.

[39] J. Sun, X. Xue, and KWE. Cheng, "Fuzzy sliding mode wheel slip ratio control for smart vehicle anti-lock braking system," Energies, vol. 12, no. 13, 2019, doi: 10.3390/en12132501.

[40] P. Upadhyaya, “A technical review on antilock breaking system (ABS)," Int. J. Recent Trends Eng. Res., vol. 3, no. 2, pp. 6065, 2017, doi: 10.4236/ica.2011.23023.

[41] V. Wanaskar, P. Shendge, and S. Phadke, "A disturbance observer based sliding mode control for anti-lock braking system," In: 2nd International Conference on Advanced Computational and Communication Paradigms, 2019, pp. 1-6, doi: 10.1109/ICACCP.2019.8882944.

[42] J. Wang et al., "Parameters design and braking efficiency analysis of a hydraulic self-energising wedge disc brake," Int. J. Precis. Eng. Manuf., vol. 18, no. 10, pp. 1409-1418, 2017, doi: 10.1007/s12541-017-0168-3.

[43] L. Xie et al., "Simulation study of automotive electronics mechanical braking system based on self-tuning fuzzy PID control," Acta Technica CSAV (Ceskoslovensk Akademie Ved), vol. 62, no. 2, pp. 819-827, 2017.

[44] W.W. Zhang et al., "Fuzzy PID control of ABS based on real-time road surface identification," Appl. Mech. Mater., vol. 597, pp. 380-383, 2015, doi: 10.4028/www.scientific.net/AMM.597.380.

[45] W. Zhang et al., "Research and Simulation of ABS Control Method," Appl. Mech. Mater., vol. 733, pp. 749-753, 2015, doi: 10.4028/www.scientific.net/AMM.733.749.

[46] J.G. Ziegler, and N.B. Nichols, Optimum settings for automatic controllers, InTech, 1995.

\section{APPENDIX}

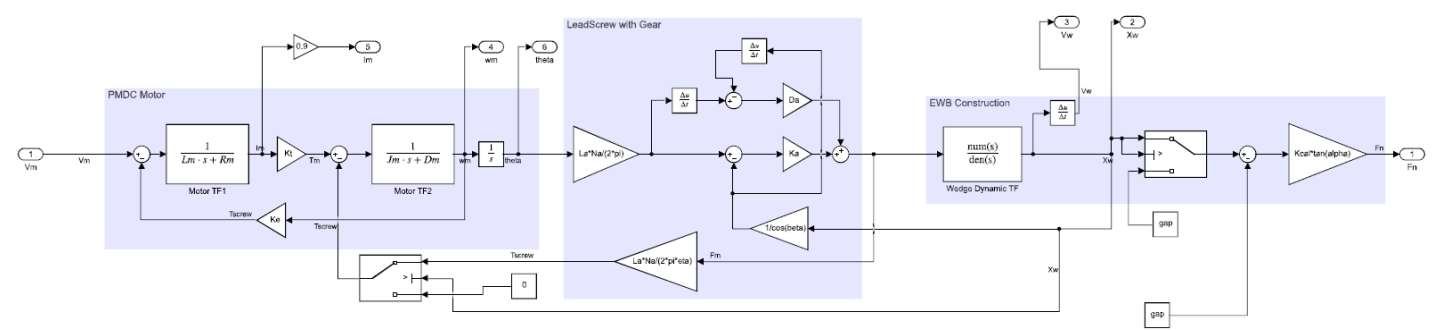

EWB Simulink model. 